\title{
The Clinical Application of Porous Tantalum and Its New Development for Bone Tissue Engineering
}

\author{
Gan Huang ${ }^{\dagger}$, Shu-Ting Pan ${ }^{+}(\mathbb{D}$ and Jia-Xuan Qiu * \\ Department of Oral and Maxillofacial Surgery, The First Affiliated Hospital of Nanchang University, \\ Nanchang 330006, China; hg3946@163.com (G.H.); panshuting314@126.com (S.-T.P.) \\ * Correspondence: qiujiaxuan@163.com \\ + Gan Huang and Shu-Ting Pan contributed equally.
}

Citation: Huang, G.; Pan, S.-T.; Qiu, J.-X. The Clinical Application of Porous Tantalum and Its New Development for Bone Tissue Engineering. Materials 2021, 14, 2647. https://doi.org/10.3390/ma14102647

Academic Editor: Sung-Hwan Choi

Received: 9 April 2021

Accepted: 13 May 2021

Published: 18 May 2021

Publisher's Note: MDPI stays neutral with regard to jurisdictional claims in published maps and institutional affiliations.

Copyright: (c) 2021 by the authors. Licensee MDPI, Basel, Switzerland. This article is an open access article distributed under the terms and conditions of the Creative Commons Attribution (CC BY) license (https:/ / creativecommons.org/licenses/by/ $4.0 /)$.

\begin{abstract}
Porous tantalum (Ta) is a promising biomaterial and has been applied in orthopedics and dentistry for nearly two decades. The high porosity and interconnected pore structure of porous Ta promise fine bone ingrowth and new bone formation within the inner space, which further guarantee rapid osteointegration and bone-implant stability in the long term. Porous Ta has high wettability and surface energy that can facilitate adherence, proliferation and mineralization of osteoblasts. Meanwhile, the low elastic modulus and high friction coefficient of porous Ta allow it to effectively avoid the stress shield effect, minimize marginal bone loss and ensure primary stability. Accordingly, the satisfactory clinical application of porous Ta-based implants or prostheses is mainly derived from its excellent biological and mechanical properties. With the advent of additive manufacturing, personalized porous Ta-based implants or prostheses have shown their clinical value in the treatment of individual patients who need specially designed implants or prosthesis. In addition, many modification methods have been introduced to enhance the bioactivity and antibacterial property of porous Ta with promising in vitro and in vivo research results. In any case, choosing suitable patients is of great importance to guarantee surgical success after porous Ta insertion.
\end{abstract}

Keywords: porous tantalum; clinical application; additive manufacturing; surface modification; bone tissue engineering

\section{Introduction}

Named after the Greek mythological figure Tantalus [1], tantalum or Ta is a rare, rigid and ductile metal element with an extremely high melting point $\left(3017^{\circ} \mathrm{C}\right)$ [2] and density $\left(16.6 \mathrm{~g} / \mathrm{cm}^{3}\right)[3,4]$. Ta has excellent biocompatibility and corrosion resistance, has been used in pacemaker electrodes, suture wire, cranioplasty plates, radiopaque markers, foil and mesh for nerve repair since the 1940s [5]. In addition, Ta has been used as single or composite coating material to modify the biological and mechanical properties of pure titanium(Ti) [6-8], Ti alloy (Ti6Al4V) [9], polyetheretherketone (PEEK) [10], cobaltchromium (CoCr) alloy [11,12], magnesium-based alloy [13], pure Fe [14] and 316 L stainless steel [15]. Recently, the advent of Ti-Ta alloy with different Ta element contents indicates a novel means to fabricate implants for bone defect restoration with improved mechanical strength, and satisfactory elastic modulus and biological properties, compared to pure $\mathrm{Ti}$ and Ti alloy [2,16,17].

Though lacking intrinsic antibacterial properties [16], Ta has a lower bacterial adhesion level and colonization compared to titanium (Ti) and stainless steel due to the spontaneously formed oxide surface layer $\left(\mathrm{Ta}_{2} \mathrm{O}_{5}\right)[17,18]$. The $\mathrm{Ta}_{2} \mathrm{O}_{5}$ layer also has been proven to facilitate the deposition of bone-like apatite coating in simulated body fluid (SBF) [19], and further accelerate the adherence of osseous and soft tissues [20]. Moreover, nanoparticles released from Ta implants have been certified to stimulate the proliferation of osteoblasts via autophagy, and the osteogenic process can further be enhanced by autophagy inducer [21]. Although the osteogenic signaling pathways of Ta have yet been fully 
explicated, several studies have focused on the TGF- $\beta$ /Smad3 [22], BMP2/Smad1 [23], Wnt/ $\beta$-catenin [22,24], Integrin $\alpha 5 \beta 1 /$ ERK1/2 [25,26] and MAPK/ERK pathways [27] that may be involved in the osteogenic effects of Ta. It is also reported that Ta can enhance the osteogenesis of diabetic rabbits by suppressing the activation of ROS-mediated P38 MAPK signaling pathway [28]. Furthermore, Ta upregulates the expression level of osteoprotegrin (OPG) and reduces that of RANKL, which means Ta also can inhibit the activity of osteoclasts [23]. The relative molecular mechanism for the osteogenic effects of Ta has been illustrated in Figure 1.

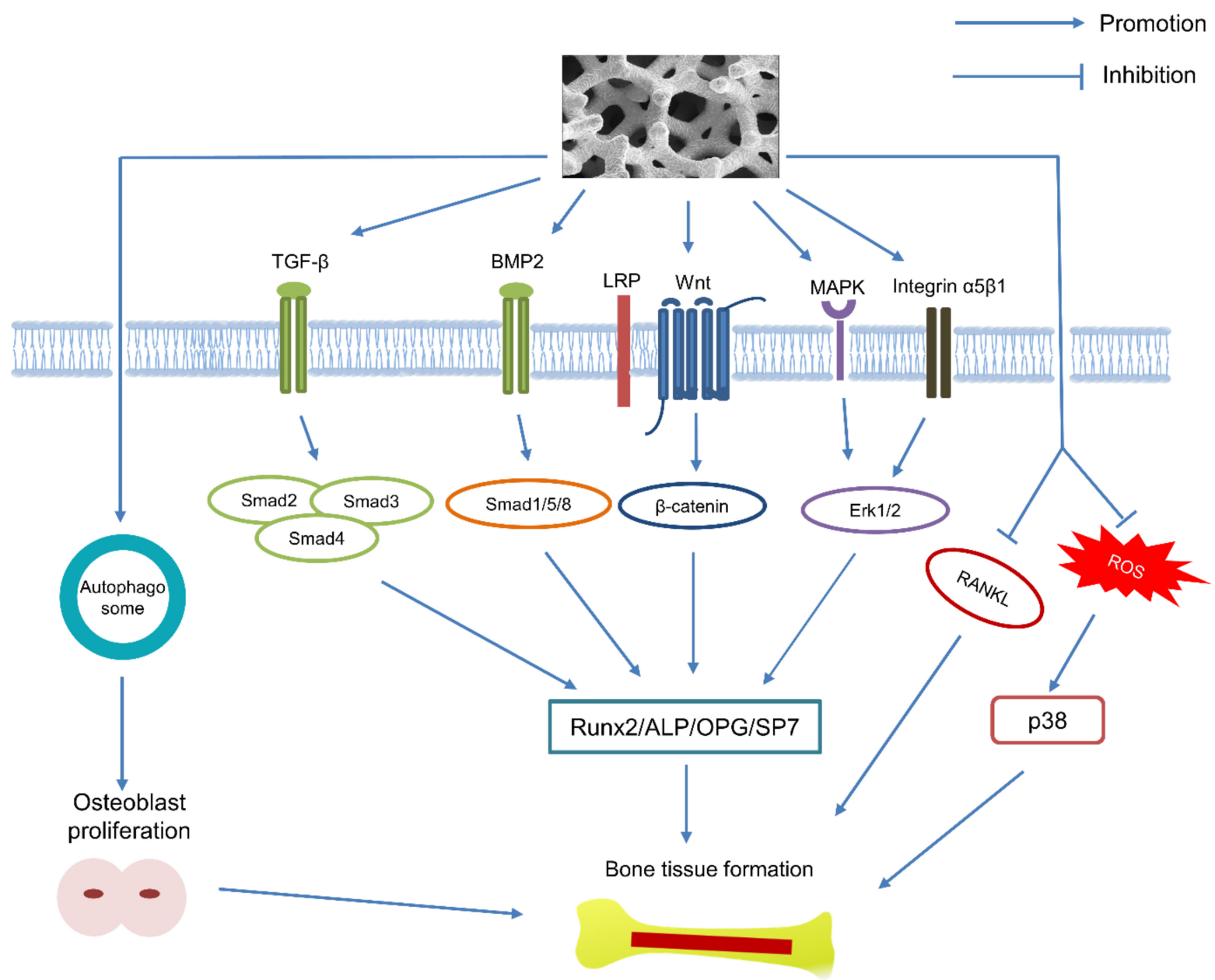

Figure 1. Schematic representation of the relative signaling pathway that may be involved in the osteogenic effect of Ta.

Compared to its solid counterpart, currently commercialized porous Ta possesses modified physical properties including high porosity (range from $75 \%$ to $85 \%$ ), dodecahedral cell structure and pore sizes ranging from 400 to $600 \mu \mathrm{m}$. It has been reported that scaffolds with an average pore size of up to $400 \mu \mathrm{m}$ and porosity of up to $70 \%$ can facilitate cell migration, proliferation, osteogenic differentiation, and blood vessel and bone tissue formation [29-32]. In this regard, the higher pore size and porosity of porous Ta can also contribute to bone and soft tissue ingrowth due to its extensively three-dimensional inner space and high pore interconnectivity [33,34]. Meanwhile, the high porosity of porous Ta ensures desirable permeability for vascularization and nutrient flow, which can guarantee rapid osteointegration at an early stage [35]. Combined with the inherent high wettability and surface energy, porous Ta can further facilitate the adhesion, differentiation and spread of stem cells [36], osteoblasts [37,38] and chondrocytes [39], as well as vascularized fibrous tissues [40] and tendon [41]. Furthermore, bone ingrowth can be found within the pores of porous Ta as early as 4 weeks after implantation [38] (Figure 2). Many in vivo studies also 
have highlighted its early osteointegration and evidenced bone ingrowth within the inner pores with Haversian remodeling in the long term [22,41-43]. In vitro, after being cultured on the porous Ta, osteoblasts obtained from old female patients ( $>60$ years) showed better proliferation and osteogenesis than those cultured on Ti fiber mesh [44], indicating the potential efficacy of porous $\mathrm{Ta}$ for the treatment of patients suffering from osteoporosis.
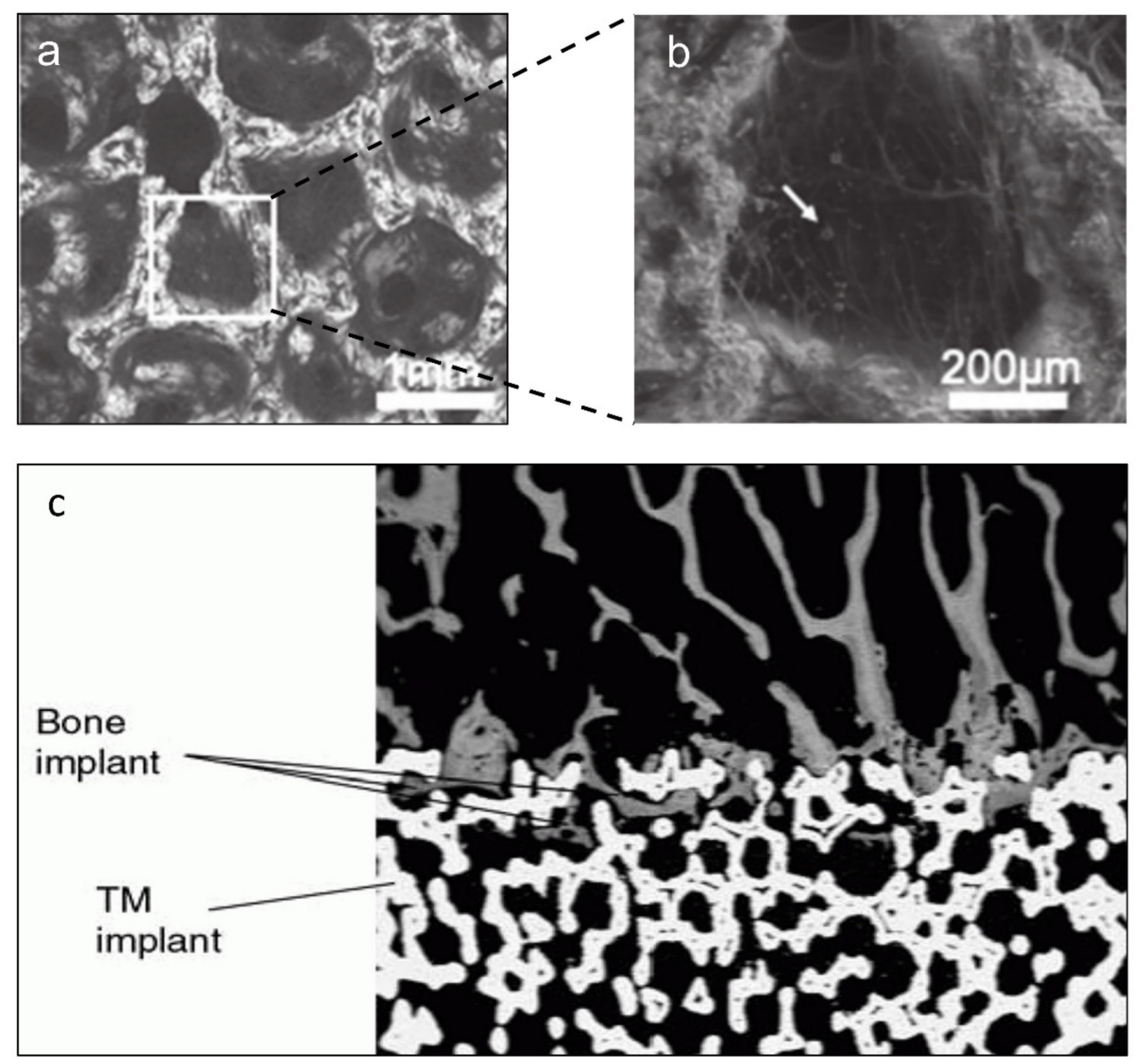

Figure 2. The microstructure of porous Ta presented as honeycomb structure (a), and cells that partially cover the cavity with many calcium nodules (indicated with white arrow) can be detected (b). Reprinted from ref. [36]. Abundant bone ingrowth can be found in the pores of porous Ta implant (c). Reprinted with permission from [45]. Copyright (C) 2021 by American Academy of Orthopaedic Surgeons.

As shown in Table 1, the mechanical properties of porous Ta can be modified to be more suitable for bone-tissue regeneration, especially for load-bearing parts of the body, via various technology due to its elastic modulus and compressive strength being much more comparable to either cortical or cancellous bones [20,33]. The satisfactory elastic modulus of porous Ta is of great importance to proportionally distribute load stress to adjacent osseous tissues, minimize stress shield effect, prevent bone resorption, and further preserve the adjacent bone stock [46]. In addition, the high friction coefficient of porous Ta also promises primary stability for the porous Ta-based implants or prostheses [42]. It is worth noting that higher pore size and porosity are associated with fine biological performance, but the mechanical strength is the opposite [43]. Therefore, attaining a balance between biological and mechanical properties of porous Ta by adjusting a rational pore size/porosity ratio is a critical challenge for future manufacturing and application. 
Table 1. The mechanical properties of osseous tissues and porous Ta produced by different techniques.

\begin{tabular}{|c|c|c|c|c|c|c|c|c|c|}
\hline $\begin{array}{c}\text { Osseous } \\
\text { Tissues }\end{array}$ & $\begin{array}{l}\text { Manufacturing } \\
\text { Technique }\end{array}$ & Porosity (\%) & Pore Size $(\mu \mathrm{m})$ & Strut Size $(\mu \mathrm{m})$ & $\begin{array}{c}\text { Elastic } \\
\text { Modulus (GPa) }\end{array}$ & $\begin{array}{l}\text { Compressive } \\
\text { Strength (MPa) }\end{array}$ & $\begin{array}{l}\text { Yield Strength } \\
\text { (MPa) }\end{array}$ & $\begin{array}{c}0.2 \% \text { Proof } \\
\text { Strength (MPa) }\end{array}$ & Ref \\
\hline Cortical bone & & $3-5$ & & & $7-30$ & $100-230$ & & & \multirow{2}{*}[47]{} \\
\hline \multirow[t]{10}{*}{ Trabecular bone } & & $50-90$ & & & $0.01-3.0$ & $2-12$ & & & \\
\hline & $\begin{array}{c}\text { CVD } \\
\text { (porous carbon scaffold) }\end{array}$ & $75-85$ & $400-600$ & $40-60$ & $2.5-3.9$ & $42-78$ & & & [33] \\
\hline & $\begin{array}{c}\text { CVD } \\
\text { (porous SiC scaffold) }\end{array}$ & $70-85$ & $150-400$ & $40-60$ & $10-30$ & $35-100$ & & & [48] \\
\hline & Foam impregnation & $65-80$ & $400-600$ & & $2.0-4.6$ & $100-170$ & & & [49] \\
\hline & Powder metallurgy & & $100-400$ & & $2.0 \pm 0.3$ & $50.3 \pm 0.5$ & & & [50] \\
\hline & LENS & $\begin{array}{l}55 \\
45 \\
27\end{array}$ & & & $\begin{array}{c}1.5 \pm 0.3 \\
7 \pm 0.6 \\
20 \pm 1.9\end{array}$ & & & $\begin{array}{c}100 \pm 10 \\
192 \pm 7 \\
746 \pm 27\end{array}$ & [51] \\
\hline & SLM & 80 & 500 & 150 & $1.22 \pm 0.07$ & $28.3 \pm 1.2$ & $12.7 \pm 0.6$ & & [52] \\
\hline & SEBM & $\begin{array}{l}75 \\
80 \\
85\end{array}$ & & $\begin{array}{l}540 \\
392 \\
386\end{array}$ & & & $\begin{array}{c}23.98 \pm 1.72 \\
19.48 \pm 1.45 \\
6.78 \pm 0.85\end{array}$ & & [53] \\
\hline & SLM & 70 & 500 & 400 & $3.10 \pm 0.03$ & & & & [54] \\
\hline & SLM & 80 & $300-400$ & & $2.34 \pm 0.2$ & $78.54 \pm 9.1$ & & & [55] \\
\hline
\end{tabular}

Notes: CVD, Chemical Vapor Deposition; LENS, Laser Engineered Net Shaping; SLM, Selective Laser Melting; SEBM, Selective Electron Beam Melting. 
The commercially available porous Ta implants fabricated via Chemical Vapor Deposition (CVD) by Zimmer Biomet Inc. (Warsaw, IN, USA), also known as trabecular metal, resemble cancellous bone due to their microstructure [33]. Meanwhile, many manufacturers, e.g., Runze Pharmaceutical Co., Ltd. (Chongqing, China) [49] and Printing Additive Manufacturing Co., Ltd. (Zhuzhou, China) [54], have also engaged in the manufacture of porous Ta. At present, additive manufacturing (AM), also known as 3-Dimensional printing or rapid prototyping, has been exploited to fabricate porous tantalum scaffolds or implants. The procedures of AM technology mainly include electron beam melting (EBM), laser engineering net shaping (LENS), and selective laser melting (SLM). Compared with CVD or other traditional subtractive manufacturing, AM exhibits superior performance with satisfactory cost-efficiency, less time and material consumption [53]. With the help of AM technology, both the macrostructure and microstructure of porous Ta can be precisely controlled, during the producing process, according to the design parameters. The Additive manufactured porous Ta scaffolds also show satisfactory fatigue strength and load-bearing capacity [56]. Moreover, many modification methods have been employed to enhance the bioactivity and antibacterial property of porous Ta for its future application in bone tissue engineering.

So far, porous Ta-based implants or prostheses have been extensively applied in orthopedics and dentistry (Figure 3, and typical products are shown in Figure 4). Therefore, the aim of this research is to review the clinical application of porous Ta-based implants or prostheses which have been implemented in orthopedics and dentistry, and summarize new manufacturing and modification methods for this promising porous biomaterial.

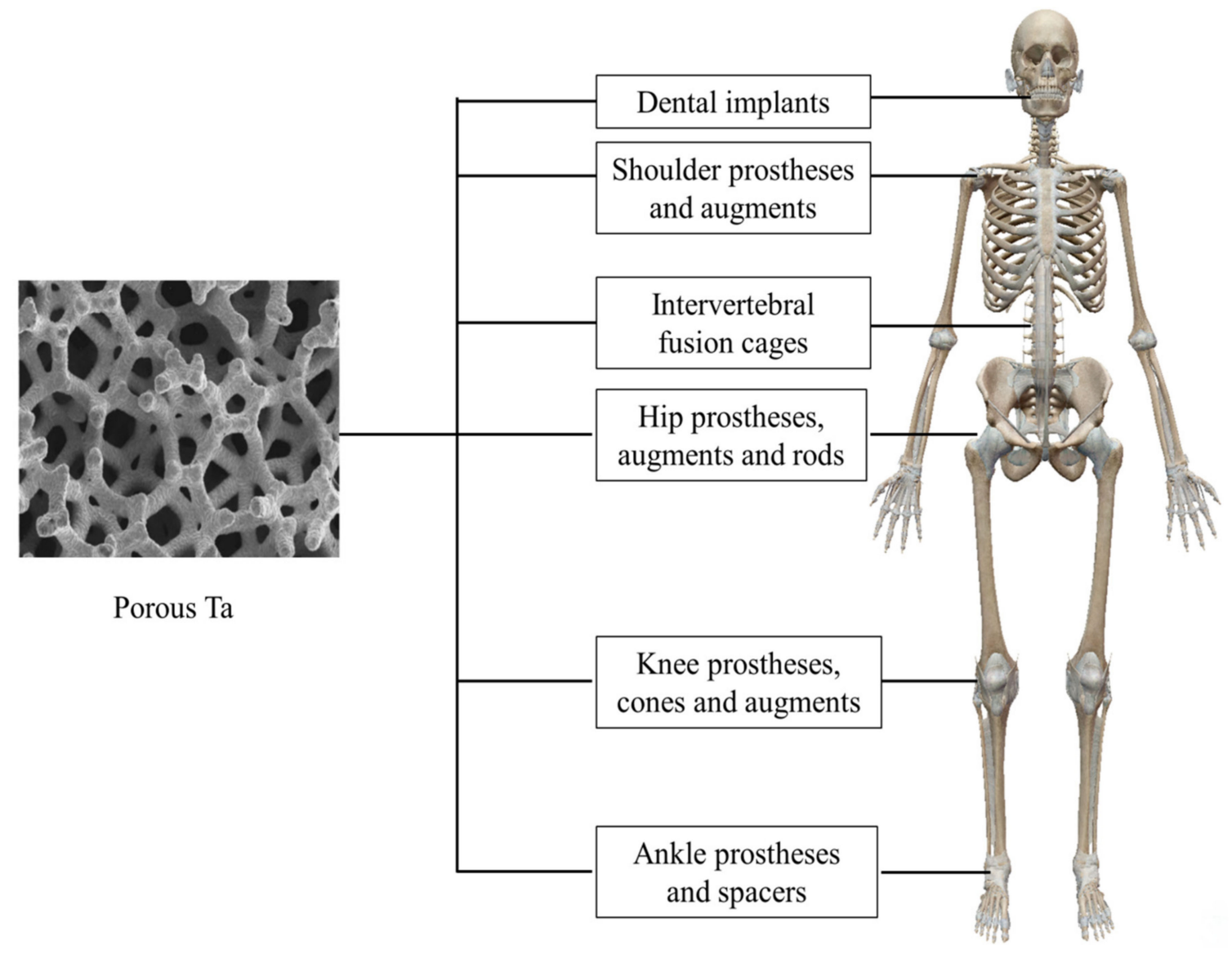

Figure 3. Application of porous Ta in different parts of the human body. 

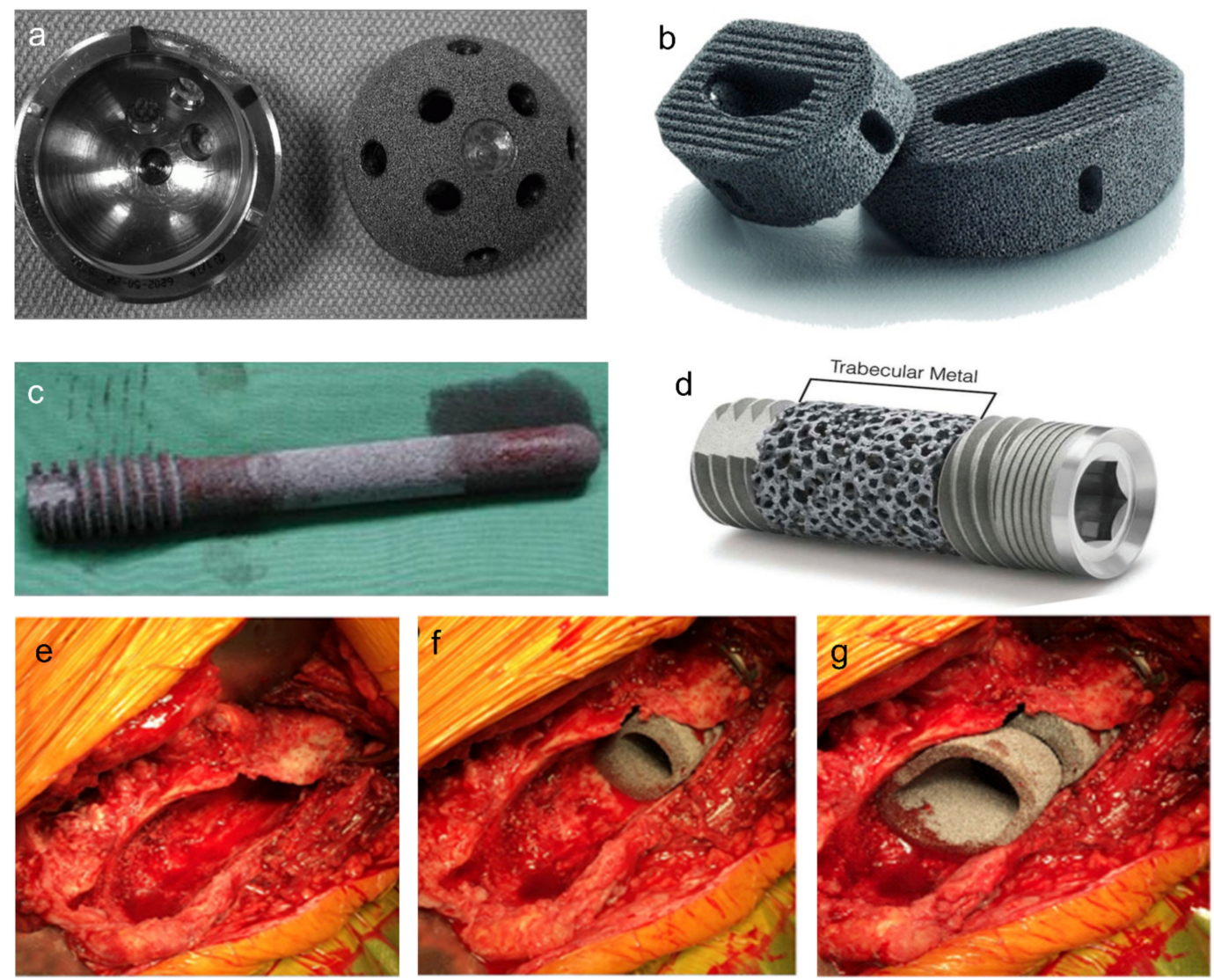

Figure 4. The typical products of porous Ta-based implants manufactured by Zimmer Biomet Inc. Acetabular cup with porous Ta coating (a). Reprinted with permission from [45]. Copyright (C) 2021 by American Academy of Orthopaedic Surgeons. Porous Ta lumbar interbody fusion cage (b) Reprinted from ref. [57], porous Ta rod (c) Reprinted from ref. [58] and dental implant (d) Reprinted from ref. [59]. The porous Ta cones were used to reconstruct femoral metaphyseal defect (e-g). Reprinted from ref. [60].

\section{Clinical Application of Porous Ta in Orthopedics and Dentistry}

\subsection{Femoral Head Osteonecrosis}

Osteonecrosis of the femoral head can be an extremely harmful disease for young and middle-aged patients who are physically active [61,62]. Therefore, appropriate measures should be taken at an early stage to preserve the femoral head before the final collapse of the femoral head and subchondral plate.

Core decompression has been applied in the salvage of the femoral head for many years, but the lack of mechanical support to the subchondral bone after debridement of the necrotic bone may further result in the collapse of the head [63]. Meanwhile, in their histopathology study, Gonzalez Del Pino et al. [64] found that the new bone formation originated mainly from the host bones rather than the vascularized grafts. In this regard, as a reasonable substitute for vascularized fibular autografts, porous Ta rod has been used as a supplementary approach to sustain the bony defect portion after core decompression [65].

Primarily designed to sustain the structure of the subchondral plate and stimulate osteogenesis of the host bone, porous Ta rod has been proven to alleviate the deterioration of femoral head necrosis and postpone the final conversion to total hip arthroplasty, in the majority of publications, for early or intermediate stage patients [65-68]. Although the efficacy of this tantalum rod remains controversial in the long-term [69], removal of the rod would be an obstacle during conversion to total hip arthroplasty [70]. The survival rates after porous Ta rod insertion is impacted by multiple factors including the stage of the disease, corticosteroid usage, osteonecrosis lesion volume and location, bone marrow edema, and joint effusion [71,72]. The presence of bone marrow edema has been proven to 
be a poor prognostic factor of femoral head osteonecrosis and also a predictor of conversion to total hip arthroplasty (THA). Furthermore, patients with bone marrow edema had a significantly higher likelihood of eventually resorting to THA [72].

It should be noted that the diameter of a porous Ta rod is only $10 \mathrm{~mm}$, which confines the supporting area of the rod; if the lesion size was larger than that diameter, collapse would occur at other areas [73]. Moreover, the histopathological analysis of 15 retrieved porous Ta rods revealed $1.9 \%$ bone ingrowth, and mechanical support for the subchondral bone was proven to be insufficient [74]. Thus, improvements in implant design and surgical technique are needed, and the patients' necrotic stages should also be scrutinized before the surgical procedure is undertaken [75]. Accordingly, many modified surgical techniques have been introduced to enhance the osteogenesis ability of porous Ta rod, including a combined technique involving bone marrow aspired from iliac crest [58], combination with vascularized bone grafting alone [76], or with bone marrow mesenchymal stem cells (BMMSCs) and vascularized autografts [77]. However, longer-term follow-up clinical trials are still desired to verify the efficacy of these modified methods.

\subsection{Hip Arthroplasty}

The porous Ta acetabular cup for primary THA is fabricated by directly compressing the ultra-high molecular polyethylene into an elliptical porous Ta shell. This kind of monoblock acetabular component design has theoretically diminished the occurrence of backside wear, and the absence of screw holes prevents the access of polyethylene wear debris, which can infiltrate the bone-implant interface, and which has long been regarded as an initiating factor resulting in aseptic loosening of the cup [78]. The porous Ta shell with low elastic modulus, high friction coefficient and excellent osteoconductivity can help to preserve or even increase the bone stock of adjacent acetabulum and, if necessary, facilitate the revision surgery [79].

In a preclinical research, 22 porous Ta acetabular components were exploited in a canine model [37]. The results revealed that the bone ingrowth depth of the 22 cups ranged from 0.2 to $2 \mathrm{~mm}$ after 6 months. Furthermore, the average bone ingrowth was $16.8 \%$ in all sections and $25.1 \%$ in the periphery; both were better than the results of another canine model study in which bone ingrowth in titanium fiber and $\mathrm{Co}-\mathrm{Cr}$ was $21.5 \%$ and $13.4 \%$, respectively [80]. Clinically, 151 hips were followed up for 8-10 years post primary THA in a prospective study [81]. Although periacetabular gaps with lengths ranging from 1 to $5 \mathrm{~mm}$ could be found in 25 hips at early stage, those gaps disappeared after 24 weeks. The follow-up radiograph verified the absence of radiolucency, osteolysis of the adjacent bone, polyethylene wear debris and cup loosening. All these indicated the design advantages of the porous Ta cup. Substantial bone deposition could be found on the surface of a retrieved acetabular component after 50 months due to dislocation in this study. However, the lack of screw holes of the cup may have hampered the direct observation of dome contact during surgery and the final seating of the cup into acetabular socket could not be accurately ensured [81].

As for revision THA, it is a surgical challenge to reconstruct acetabulum with huge bone defects and to restore the primary stability, rotational center and maximal boneimplant contact [82]. Porous Ta acetabular prostheses has been revealed as an optimal option to cope with these formidable challenges [83-87]. The modular design of the porous Ta revision prosthesis provides augmented or buttressed sections to be screwed onto the supra-acetabulum for bone defect reconstruction; subsequently, the elliptical cup is implanted in the acetabular socket against the section with cement laying at the interface of the two components [88]. Many short and medium-term studies have shown promising results of the modular porous Ta acetabular shell and augmentation in the treatment of acetabular dome defects with or without osteolysis of ischium, teardrop and Kohler line disruption (Paprosky type II or III) $[85,87,89-94]$. A ten-year follow-up after revision surgery with porous Ta shell and augmented implantation was conducted by Löchel et al. [95]. The survival rate of 51 patients (53 hips) who had completed the follow-up was $92.5 \%$, with a 
significant increase in Harris Hip Score (55 before surgery vs. 81 post surgery) after the revision surgery. Meanwhile, the authors strongly recommended the application of screws toward the load transferring and inferior direction in every patient with acetabular defects to stabilize the shell and augmentation, diminish the fretting at the interface of shell-host bone or shell-augmentation and guarantee the primary stability of the long-term survival rate [95]. In addition, porous Ta acetabular implants and augmentations were suggested in the reconstruction of the hip joint after resection of peri-acetabular tumors, in order to ensure satisfactory clinical results at early stage [96]. The irradiated pelvis was reported to always be associated with high aseptic loosening rates of acetabular components [97-99]. Even so, porous Ta cups still obtained satisfactory results in THA treatment of irradiated pelvis owing to their high friction coefficient and porous microstructure, as well as rapid bone ingrowth rate [97-99]. However, it is imperative to note that transverse acetabulum fracture may occur during or after the revision surgery if excessive reaming is performed to insert large cups (average $58 \mathrm{~mm}$ ) during the operation [100,101].

\subsection{Knee Arthroplasty}

Porous Ta prosthesis for keen primary and revision reconstruction comprises the monoblock tibial component, the tibial or femoral cone and augmentation, as well as the patella prosthesis. The design of the monoblock tibial component for primary arthroplasty is similar to that of the monoblock acetabular component, with the polyethylene directly compressed into a porous Ta baseplate, which also eliminates the potential occurrence of wear debris infiltrating into bone-implant interface. The mechanical and biological properties of porous Ta guarantee the primary stability of the tibial component and ensure its long-term survival rate [102]. Several short and long term results have shown encouraging efficacy of this cemented or uncemented monoblock tibial component for the treatment of relatively young and active patients [103-108]. A histological analysis of a retrieved porous Ta tibial component from a chronically infected knee prosthesis revealed significant bone ingrowth in the posts and post-baseplate interface rather than baseplate, suggesting that fine bone-implant integration could still be obtained even in the infected environment [109]. However, caution should be taken with patients who have heavy weight (average $241.9 \mathrm{lbs}$ ) and tall height (average $71.8 \mathrm{inch}$ ) and have previously received total knee arthroplasty (TKA) with cementless porous Ta tibial prostheses, as this patient group may easily encounter early medial collapse due to the overload cyclically posed on the medial portion of the tibial prosthesis [110].

Severe distal femoral and proximal tibial bone defects are the greatest challenge in revision total knee arthroplasty. Without adequate bony support and inferior bony structure, the collapse of the tibial or femoral component will inevitably occur. Therefore, porous Ta cones for substitution of tibial and femoral metaphyseal bone defects have been introduced to function as structural grafts, to enhance bone stock, and to regain normal articular alignment with multiple flexibilities for different sizes and positions of bone loss [102,111]. The results of a 5-year study reported by Potter et al. [112] indicated that porous Ta femoral cones could effectively fill the metaphyseal defects of the distal femur and sustain the femoral component after revision TKA. Another five to nine year follow-up study supported the efficient application of porous Ta tibial cones for the restoration of huge osseous loss and facilitated early weight-bearing [113]. However, long-term and comparative analysis is still needed to further verify the viability of these porous cones for massive metaphysis defect reconstruction, and the high price per cone (approximately \$4.000) would impede their clinical application at a large scale [114].

Restoring the normal function and structure of the patellofemoral joint will be an integral portion in TKA or revision TKA if the extensor mechanism has been impaired due to patellar resection or severe osseous deficiency. Owing to its capability to favor soft tissue and bone ingrowth [38,40], porous Ta patellar prosthesis has been used to reconstruct the fulcrum role of patella [115]. However, the stability of this novel patellar prosthesis depends mainly on the residual bone stock of patella, rather than soft tissue [116]. 
Moreover, abundant bone-implant contact and blood supply to the residual patella are critical factors for the long term success of porous Ta patellar prosthesis [117]. Therefore, prudent selection of proper patients should be the prior step before definite surgery is performed, so as to avoid the recurrence of complications such as persistent pain, weakened extensor mechanism, and patellar shell fracture.

\subsection{Shoulder Arthroplasty}

Glenoid component loosening is always a disturbing complication of total shoulder arthroplasty (TSA) or reverse total shoulder arthroplasty (RTSA) despite various methods having been implemented to address it [118-122]. Based on the successful experience in hip and knee arthroplasty, the porous Ta baked monoblock glenoid component has been introduced for TSA [123] and RTSA [124], utilizing the properties of rapid osteointegration and high friction coefficient of porous $\mathrm{Ta}$, which can elongate survivorship of the shoulder prosthesis in the long-run.

Budge et al. [123] reported that prosthetic fracture of the first generation of the porous Ta glenoid component occurred in 4 of 19 patients after 30 months. All four glenoid component fractures appeared at the interface of the keel and the metal plate, indicating a combined effort of cyclic loading and insufficient bony support to the glenoid portion of the prosthesis that finally ignited the fatigue failure at the junction of the keel and the metal plate [123]. Therefore, emphases should be placed on gaining a compacted press-fit pattern of the metal component in surgery [125]. Reinforced with anterior-posterior keels and extended interdigitating at the interface of polyethylene tray and porous Ta plate, the redesigned second generation of porous Ta glenoid prosthesis is introduced to cope with the annoying keel-glenoid plate junction fracture that frequently occurred in the first generation [126].

Improved clinical performance of the second generation porous Ta glenoid component was revealed in 40 patients who were followed up for 38 months post TSA [126]. Significant progress of shoulder function scores were found in all 40 patients without conspicuous prostheses loosening, migration or fracture [126]. After 76 shoulders were replaced with porous Ta glenoid components and followed up for an average of 43.2 months, Panti et al. [127] also reported satisfactory clinical results in terms of improved range of motion, pain relief and advanced function scores with the absence of severe complications such as implant fracture or loosening. The mechanism behind the successful results obtained in the two aforementioned studies mainly depended on the amplified cruciform pegs, which guaranteed the compact press-fit mechanism of the glenoid component in the host bone without cement, and effectively withstood the eccentric loading force that was exerted. Meanwhile, the expanded interlocking between polyethylene tray and porous metal plate helped to resist debonding force and diminish the possibility of potential glenoid component fracture.

Nevertheless, it should be noted that the monoblock porous Ta glenoid component may cause trouble when revision TSA is to be performed, for it would be difficult to be removed due to the stable bone-implant interlocking and substantial bone ingrowth even associated with infected host bone [128], and may subsequently result in central osseous defect or scapular fracture [125]. Still, accumulated metallic debris deposition derived from the porous Ta component with a time-dependent pattern can still be found after anatomic shoulder arthroplasty, which means that mechanical failure remains a threat in terms of long-term survival rate, and that regular radiographic follow-up should be implemented to verify the stability of the porous Ta glenoid component [129].

Superior migration of greater tuberosity is a critical factor, which often results in surgical failure after shoulder hemiarthroplasty in the treatment of complex proximal humeral fractures. The migrated great tuberosity is the main cause of subacromial impingement, shoulder joint stiffness and persistent pain [130]. Humeral stem prostheses fabricated with porous Ta have been proposed to accelerate the anatomic union of greater tuberosity, which can effectively minimize the occurrence of greater tuberosity malposition after surgery and ensure eventual surgical efficacy [131,132]. 
In addition, porous Ta glenoid augmentations have recently been used to correct glenoid retroversion, with satisfactory efficacy, in 10 patients undergoing repositioning of the retroverted glenoid to a neutral position [133]. Glenoid retroversion caused by dysplasia or degenerative deformity can lead to eccentric loading, permanent posterior subluxation of the humeral head and severe prosthetic failure [133]. Therefore, porous Ta glenoid augmentation can be an optimal approach to correct glenoid deformity, though more evidence is desired to verify its exact efficacy.

\subsection{Spine Intervertebral Fusion}

The efficacy of porous Ta cages applied in anterior cervical spine fusion has been confirmed in a prospective randomized controlled clinic trial conducted by FernándezFairen et al. [134]. Compared with traditional autologous iliac bone graft combined with anterior plating, the porous Ta cage insertion group showed an equivalent fusion rate $(89 \%$ vs. $85 \%$ ) and post-surgery stability at the end point of a 2-year follow-up, but additional fixation and graft harvesting-related injuries no longer occurred [134]. After 11 years of follow-up, the clinical and radiological results of patients who had received single porous Ta cage insertion for interbody fusion remained satisfactory despite the subsidence of implants, presented within $2-3 \mathrm{~mm}$, occurring without significant complication in 12 patients [135]. Furthermore, several observational studies had also affirmed the efficacy of porous Ta in terms of interbody fusion rate, low complication rate and improved short or long term post-surgery evaluation scores including the SF-36, neck disability index (NDI) and visual analog score (VAS) [136-138].

On the contrary, another prospective randomized multicenter study showed a frustrating fusion rate of the stand-alone porous Ta device insertion group compared to the iliac crest autograft group (44\% vs. 100\%) after a 2-year follow-up [139]. In addition, the histological analysis of two retrieved tantalum blocks from patients diagnosed as nonunion at 6 months and 12 months, respectively, revealed substantial fibrous ingrowth instead of bony tissues [139]. Similarly, Löfgren et al. [140] found a significantly lower fusion rate of porous Ta than iliac crest bone grafting (69\% vs. $92 \%)$. Considering potential nonunion, Wigfield et al. [141] terminated their prospective study prematurely due to radiolucent lines appearing at the anterior-inferior border of porous Ta implants in four patients, implanted with either blocks or rings, at 6 weeks, though the lucent lines disappeared 12 months post-surgery and the final outcomes of the porous Ta insertion group were better than the autologous bone grafted group.

Accordingly, two meta-analyses [142,143] have recently analyzed the intro-operation and post-surgery parameters including operating time, blood loss, hospital stay, fusion rate, NDI and VAS scores, as well as satisfaction and complication rates of relative clinical trials. Through the two meta-analyses, it has been established that porous Ta implants possess the same efficacy and safety in the surgical treatment of anterior cervical degenerative disc diseases as autologous iliac bone grafting, which has long been regarded as the gold standard $[142,143]$. However, more randomized controlled trials with large samples are still desired to reinforce the clinical evidence of porous Ta implants.

In addition to a high friction coefficient, porous Ta can offer suitable conditions for rapid bone ingrowth [34], which further guarantees its long-term stability for lumbar intervertebral fusion either with or without the augmentation of pedicle screws [144]. Lequin et al. [145] used standalone porous Ta cages in the treatment of 26 patients suffering from recurrent lumbar disc herniation. Though moderate satisfactory clinical results were revealed and significant relief of back and leg pain was only reported in $46 \%$ of patients, $85 \%$ of patients showed remarkable improvement in their working-status at 1 year postsurgery [145]. Meanwhile, Lebhar et al. [146] and Butler et al. [57], respectively, reported reliable clinical, functional and radiographic results after the application of porous $\mathrm{Ta}$ implant for lumbar intervertebral fusion in their retrospective cohort studies.

Furthermore, in a randomized controlled trail (RCT), 80 patients were either enrolled into a standalone porous Ta cage fusion group or a pedicle screws-supplemented 
group [147]. Similar clinical evaluation results including the Oswestry Disability Index (ODI), VAS and SF-36 scores, were revealed at a 2-year follow-up point [147]. Furthermore, equivalent $X$-ray results of both groups evaluated at 6-year follow-up proposed that porous Ta standalone fashion could provide stability for lumbar spine interbody fusion without additional fixation or bone grafting [147]. However, RCTs are still rarely used to definitely corroborate the clinical value of porous Ta cages for lumbar spine fusion surgery used either in a standalone fashion or augmented with posterior screws. In addition, the radiopaque property of tantalum makes the radiographic examination of the intervertebral bone fusion rate difficult.

\subsection{Ankle Arthrodesis and Arthroplasty}

As with femoral head osteonecrosis, the end-stage ankle arthritis can also be a very severe and debilitating disease for younger and active patients $[148,149]$. Therefore, surgical intervention, e.g., ankle arthrodesis and total ankle arthroplasty, should be taken into consideration when conservative methods have failed.

Regarded as a promising alternative to traditional bone autograft or allograft, porous Ta spacer has been applied in ankle arthrodesis without the limits of size, volume and source [150-153]. Furthermore, the cost of a single porous Ta spacer (approximately \$989.5-1000) has been reported to be approximately comparable to that of an iliac crest autograft (approximately $\$ 600-700$ ) and an allograft (approximately $\$ 850$ ); however, the latter two may take more time for preparation during the surgery [150-152]. The porous Ta spacer is an optimal choice for reconstruction surgery, and is especially suitable for huge bone defects $[154,155]$. This is the case because it has adequate structural strength to maintain the restored height and angular correction of the ankle joint until the appearance of osseous fusion between the porous Ta spacer and adjacent bony tissues $[33,151]$, which is significantly different from bone autografts or allografts, either of which may collapse due to absorption after implantation $[45,146,152]$. Moreover, as with cancellous bone, the porous Ta spacer provides the necessary space and osteoconductive environment for vascularized bone tissue ingrowth, obviating autograft-related harvest lesions $[156,157]$ and allograft-related infectious diseases [153].

The clinical results of porous Ta spacers used for the salvage of failed total ankle arthroplasty are also favorable [151,152,155]. More often, accompanied by nonunion, leg shortening, infection or even severe bone defect after debridement, failed total ankle arthroplasty can be difficult reasonably address $[158,159]$. To enhance the fusion efficiency of porous Ta spacer, Sundet et al. [160] combined the use of retrograde nailing, a porous Ta spacer and an osteoinductive pad augmented with autologous bone marrow concentrate for revision surgery of 30 patients ( 31 ankles) with failed total ankle arthroplasty. The mean fusion rate at the average 23 -month follow-up was $93.5 \%$, and the vast majority of patients were satisfied with the surgery in terms of pain relief and improved activity, though additional expenditure were entailed in this clinic trail [160]. Similarly, Kreulen et al. [155] introduced a new surgical strategy for reconstruction surgery of two patients with failed total ankle arthroplasty and four patients with ankle collapse post infection. In this study, porous Ta spacers were also augmented with autologous bone marrow obtained through the Reamer/Irrigator/Aspirator technique from the femoral marrow cavity and fixed with tibiotalocalcaneal nail, and the bone morphogenetic protein 2 (BMP-2) or platelet derived growth factor was further supplemented to boost bony fusion. With the help of this novel method, thorough osseous fusion at the implant-bone interface appeared at the early stage of 4-6 weeks post-surgery and no failure cases were observed [155]. In contrast, Aubret et al. [159] reported disappointing outcomes after the insertion of porous Ta spacers. Even augmented with iliac crest autograft and allograft bone chips for revision of failed total ankle arthroplasty in 10 patients, two patients had failed integration of porous Ta spacers, one patient presented with talocrural joint nonunion and three patients needed secondary revision surgery due to severe pain. However, the main reason for these failed 
cases was supposed to be the weak fixation strength provided by nails compared with $6.5 \mathrm{~mm}$ screws [151] or reconstruction plates [158].

Despite being reported as having a lower survival rate than hip and knee arthroplasty [161-163], total ankle arthroplasty (TAA) has been suggested to preserve the mobility of ankle joint and normal gait instead of being fused with triple arthrodesis which has long been considered as the gold standard for the treatment of end-stage ankle arthritis.

A newly designed porous Ta-based total ankle prosthesis was approved by the Food and Drug Administration in 2012 and marketed by Zimmer Biomet Inc. [164,165]. Combined with the use of porous Ta-based ankle prosthesis in TAA, promising prognosis can be foreseeable in terms of pain relief and functional improvement in the short-term, even without supplementation with cement augmentation, due to the fact that the stability of tibial and talar components mainly depends on bony interlocking between the porous Ta base and the host bone [164-170]. Moreover, the pattern of porous Ta bases of the two components resembles that of the subchondral bone of tibia and talus and can distribute loading stress rationally and diminish the occurrence of peri-implant osteolysis, which often resulted in aseptic loosening of the implants $[165,171]$. This novel ankle prosthesis is implanted through the lateral approach, associated with distal fibular osteotomy, which theoretically offers direct exposure to both the sagittal and coronal plane of the tibiotalar joint and obviates surgery-related neurovascular injuries [171]. Incorporated with an extramedullary alignment frame, the innovate surgery approach can minimize the amount of bony resection, optimize tibial and talar components positioning and preserve the bone-implant contact area, all of which finally guarantee the survival rate of porous Ta ankle prosthesis [164].

The histological analysis of this porous Ta-based ankle prosthesis retrieved from a 50-year old female patient revealed that the bone ingrowth percentage in tibial and talar components was more than those found in the retrieved porous Ta hip and knee components [172]. Meanwhile, active bone remolding was found within the porous Ta layer even at 3 years post-surgery. However, regional osteolysis and metal wear debris could not be avoided, both of which did not jeopardize the stability of the prosthesis. Nevertheless, decreased bone density of distal tibia adjacent to the tibial component still presented in this patient, indicating that the stress shielding effect and related bone resorption could not thoroughly be eradicated through the use of porous Ta-based ankle prosthesis [172].

\subsection{Dental Implants}

Aimed to increase surface energy, extend the bone-implant contact area, improve surface hydrophilicity and facilitate mesenchymal cells' or osteoblast progenitor cells' adherence, the surface roughness design of dental implants has now become very widely used and has been proven to enhance the progress of osteointegration and angiogenesis [173,174]. Therefore, the spongy bone like structure of porous Ta could be one explanation for its superior biological and mechanical property to many other metal materials in terms of rapid osseous ingrowth and bone-to-implant contact, both of which directly influence the survival rate of dental implants in the long run [175]. The histological and histomorphometric analysis has validated the osseoincorporation property of porous Ta implants derived from the rapid formation of vascularized bone tissues not only on the surface but also in the inner pores, which further reinforced the interlocking force between the implants and human jaws [176]. The canine model test revealed that the porous Ta section could provide a more rapid new bone formation and stronger stability for the porous Ta enhanced titanium implants compared to its conventional screwed titanium counterparts [177].

The porous Ta-enhanced tianium dental implant is now considered to be an effective therapeutic method for implanting treatment of certain patients associated with periodontitis [178], alveolar bone defects [179] and even maxillofacial tumors [180,181]. The porous Ta segment can provide an expanded three-dimensional space for the infiltration and differentiation of osteoblasts as well as the accumulation of vascular endothelial cells [40,182]. In addition, this novel implant has also been used in immediate revision surgery for previ- 
ously failed dental implantation based on the superior osteointegration of porous Ta [183]. The immediate loading tests of porous Ta enhanced implants demonstrated significantly less marginal bone loss than that of threaded implants $(0.43 \pm 0.41 \mathrm{~mm}$ vs. $0.98 \pm 0.67 \mathrm{~mm})$ after 1-year of functional loading [184]. This result was then further corroborated in a retrospective study in which an average of $0.28 \mathrm{~mm}$ bone gain could be found in the porous Ta enhanced group, but the Ti group showed an average of $0.2 \mathrm{~mm}$ marginal bone loss after 1-year of implant loading [185].

However, mechanical flaw of this porous Ta enhanced dental implants may be located at the junction of the middle and distal third portion, for the middle portion is produced as slender sharp in order to accommodate the porous Ta sleeve and is welded to the distal apex portion [186]. Accordingly, potential fragile fracture may occur at this facet when the implant is to be inserted in the socket of maxilla or mandible with high bone density. Meanwhile, the unsterile oral cavity, where more than 500 kinds of bacteria are harbored, can be a challenge for the dental application of porous Ta [186]. Therefore, in-depth studies that can enhance the antibacterial property of porous Ta are still needed because the microbial environment of oral cavity and orthopedic sites is obviously different.

\section{New Development of Porous Ta for Bone Tissue Engineering}

\subsection{Additive Manufactured Porous Ta}

Except for conventional techniques including CVD [33,48], foam impregnation [49] and powder metallurgy [50], various additive manufacturing methods have been introduced to produce novel porous Ta scaffolds with different pore size and porosity, but comparable mechanical properties with human cortical and trabecular bones [47] (Table 1). Comparison tests performed with cellular and animal models have revealed similar or even better biological and mechanical performance of printed porous Ta scaffolds than their porous Ti counterparts with the same porosity and pore diameter (Table 2) $[51,52,54,55,187]$. Moreover, as a high-end technique, additive manufacturing can help manufacturers to produce porous Ta implants with tailored pore size and porosity to resist different biomechanical loading stress in different parts of the human body. Incorporated with Computer Aided Design (CAD) software, additive manufacturing thus makes personalized porous Ta implants or prostheses for individual patient possible. Recently, several printed porous Ta products have successfully been applied in clinical settings.

Wang et al. [188] have designed and produced a printed porous Ta knee prosthesis for revision surgery for an 83-year old female patient suffering from chronical inflammation and unendurable pain of the left knee after a previous total knee arthroplasty (Figure 5). The X-ray showed severe bone defect in the medial tibial plateau, varus deformity of the left knee and loosening of the tibial component, all of which were formidable challenges to be addressed by conventional surgical techniques. With the help of CAD, the authors corrected the anatomic alignment of the left lower limb and fabricated personalized knee prosthesis which can precisely match the bone defect area for the definite revision surgery. Twelve months after the final revision surgery, the patient recovered to normal activity with no more complaints about the affected limb. After that, the same team fabricated personalized porous Ta fibular and femur implants for reconstruction surgery following the same design and manufacturing process [53]. 
Table 2. The biological properties of additive manufactured porous Ta scaffolds.

\begin{tabular}{|c|c|c|c|}
\hline Porosity\%/Samples & In Vitro Tests Results & In Vivo Tests Results & Ref. \\
\hline $80 \%$ Ta & $\begin{array}{l}\text { Cytotoxicity test (L929 mammalian cells) } \\
\text { - No cytotoxicity }\end{array}$ & $\begin{array}{l}\text { Histological evaluation (rat femur defect model) } \\
\text { - The bone defect can be bridged by the new bone with the help of printed } \\
\text { porous Ta scaffold. } \\
\text { Torsion test } \\
\text { - Rigid bone-implant connection can be obtained. }\end{array}$ & [52] \\
\hline $70 \%$ Ta vs. $70 \% \mathrm{Ti}$ & $\begin{array}{l}\text { Cell morphologies (hBMSCs) } \\
\text { - Cells' adhesion, proliferation and vitality were similar. } \\
\text { Cell differentiation } \\
\text { - } \quad \text { ALP and mineralized nodule staining levels were comparable. } \\
\text { Quantitative RT-PCR Analysis } \\
\text { - Sp7 and OCN genes levels were comparable. }\end{array}$ & $\begin{array}{l}\text { Histological evaluations (rabbit distal femoral defect model) } \\
\text { - } \quad \text { Bone ingrowth rate and depth were similar in the two groups. } \\
\text { - Ti group showed a quick-slow-quick new bone formation pattern. } \\
\text { - Ta group showed a gradual slowdown style of new bone formation. } \\
\text { Push out test } \\
\text { - The two groups had similar push out force. }\end{array}$ & [54] \\
\hline $80 \%$ Ta vs. $80 \%$ Ti & $\begin{array}{l}\text { Cell morphologies (hBMSCs) } \\
\text { - Ta group showed better cell viability than Ti group. } \\
\text { Cell proliferation } \\
\text { - Ta group was higher than Ti group after 5-7 days. } \\
\text { Cell differentiation } \\
\text { - Ta group had superior ALP levels and calcium nodule numbers. } \\
\text { Quantitative RT-PCR Analysis } \\
\text { - Levels of Runx2, ALP, Col-1, OCN and OPN genes were higher in } \\
\quad \text { Ta group. }\end{array}$ & $\begin{array}{l}\text { Histological evaluations and fluorescence labeling (rabbit distal femoral } \\
\text { defect model) } \\
\text { - Ta could stimulate new bone formation as early as } 4 \text { weeks. }\end{array}$ & [55] \\
\hline
\end{tabular}


Table 2. Cont

Porosity\%/Samples

In Vitro Tests Results

$30 \%$ Ta vs. $30 \%$ Ti modified

with $\mathrm{TiO}_{2}$ nanotubes,

$30 \% \mathrm{Ti}$ and solid $\mathrm{Ti}$

Not mentioned
In Vivo Tests Results

Ref.

Histological analysis (rats distal femur model)

- Ta group had the most significant bone formation after 12 weeks.

Push out test

- Four groups had similar bone-implant interlocking strength.

FESEM micrographs

- Ta groups had persistent bone ingrown in the pores at 12 weeks.

- $\quad$ Ti modified with $\mathrm{TiO}_{2}$ nanotubes groups showed comparable seamless bone-implant interface with Ta groups.

- The other two Ti groups had inferior bone-implant contact.

\section{Cell morphologies (hFOB CRL-11372)}

- $\quad$ Ta groups presented more flattened cell morphologies, filopodia extensions and mineralization than Ti group.

$27 \%$ Ta and $45 \%$ Ta vs. $27 \% \mathrm{Ti}$
Cell proliferation

- Cells proliferated rapidly on Ta samples instead of Ti samples.

Immunochemistry

- $\quad$ Porous Ta facilitated cells' adhesion and differentiation via a porosity-dependent pattern. 


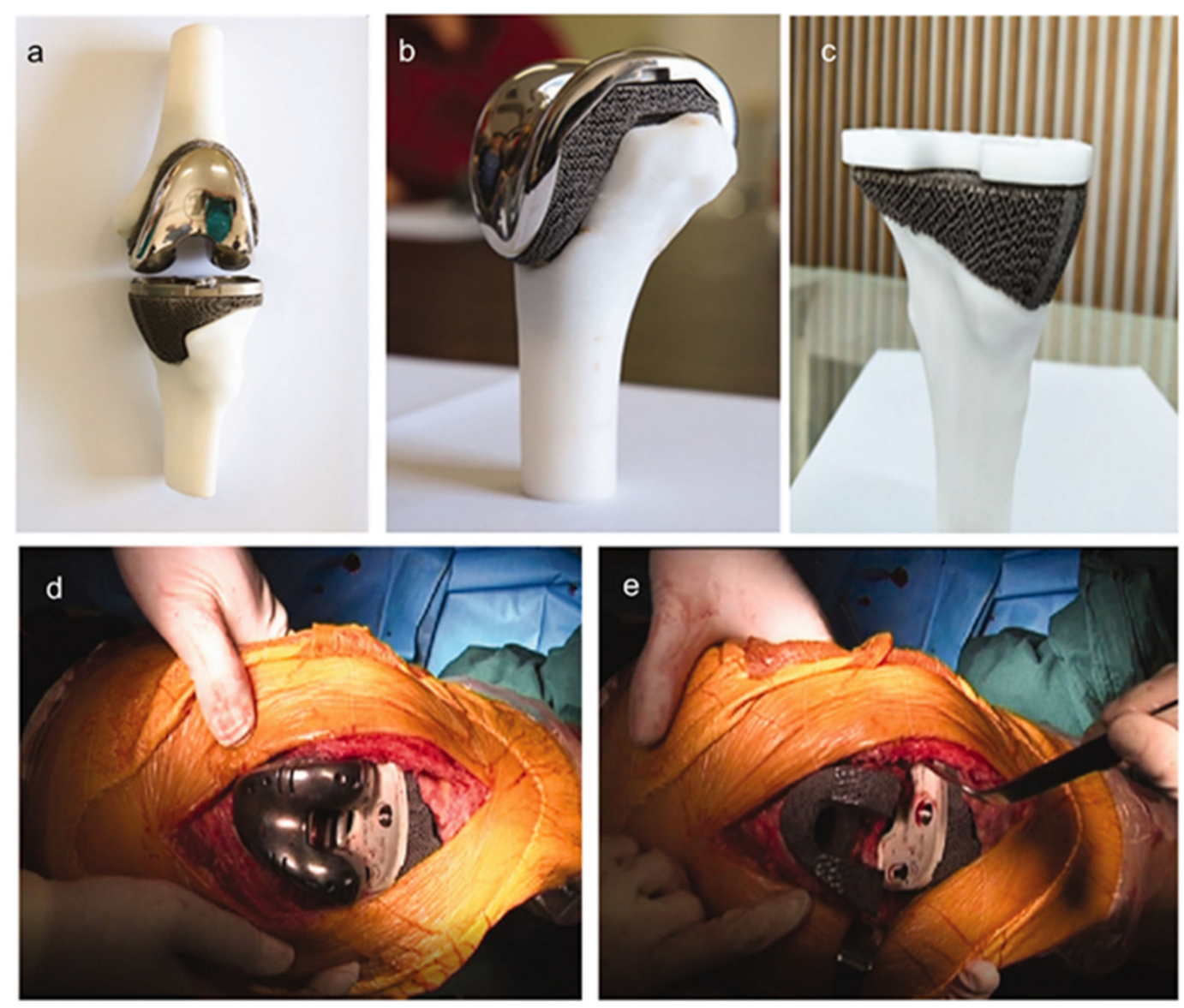

Figure 5. The printed personalized porous Ta knee prosthesis (a), distal femoral component (b) and proximal tibial component (c). The porous Ta prosthesis was inserted into distal femur and proximal tibia, respectively, during the surgery (d,e). Reprinted from ref. [188].

Developmental dysplasia of the hip (DDH) can lead to degenerative osteoarthritis of the hip in adults due to the malposition of acetabulum and femoral head [189]. In order to restore normal acetabular coverage of the femoral head and acetabulum index, the additive manufactured porous Ta acetabular patch was introduced in the treatment of eight adult DDH patients with Crowe type I [190]. Each individualized porous Ta acetabular patch was designed by Mimics 17.0 and 3-matic 9.0 software (Materialise, Leuven, Belgium) before surgery. Then, the loading stress distribution between the acetabulum restored by porous Ta patch and the femoral head was analyzed by Ansys 17.0 software (Ansys, Canonsburg, PA, USA). If the stress distribution was uniform, the designed porous Ta acetabular patch would be printed for the final surgery. After an average follow-up of 8.2 months, the VAS scores of eight patients were drastically decreased ( $2.92 \pm 0.79$ before surgery vs. $0.83 \pm 0.72$ after surgery). Meanwhile, the Harris scores (69.67 \pm 4.62 before surgery vs. $84.25 \pm 4.14$ after surgery) and the results of gait analysis were greatly improved after the implantation of the porous Ta patch.

A printed porous Ta osteosynthesis plate has been used for the treatment of a 30-year old male patient with tibial nonunion [191]. The patient had undergone intramedullary nail fixation three times previously, but failed to attain healing even associated with the iliac crest autograft. Owing to its biological and biomechanical advantages, this novel porous Ta plate ( $80 \%$ porosity, $1.5-10$ GPa elastic modulus) reunited the tibial shaft fracture uneventfully 5 months after the fourth surgery, and the patient regained normal mobility (Figure 6). 


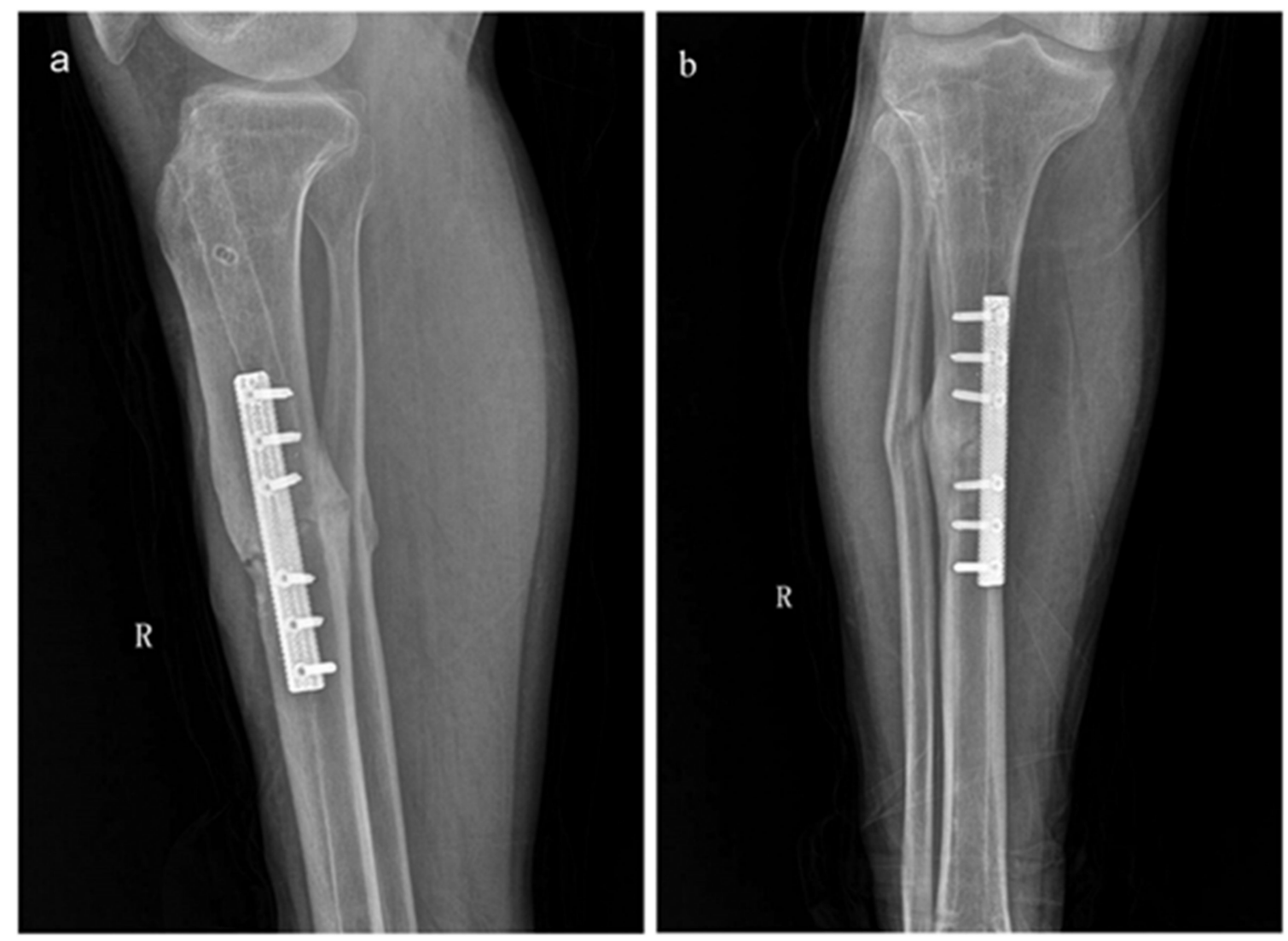

Figure 6. The AP (a) and lateral view (b) of X-ray examination at 5-month follow-up showed that the fracture healed after the implantation of the printed porous Ta osteosynthesis plate. Reprinted from ref. [191].

Nevertheless, the high demand and high price of the medically applicable tantalum powder used to produce porous Ta products are the main negative factors that hinder the extensive clinical implementation of novel porous Ta implants or prostheses.

\subsection{Surface Modification}

The critical drawbacks that may impede the further application, in bone tissue engineering, of porous Ta are its inertness and low level of bioactivity. Therefore, various methods have been introduced to modify porous Ta for further clinical application (Table 3). These methods can mainly be cataloged into biomaterial coating and surface treatment, all of which are aimed to endow porous Ta-based implants or prosthesis with improved osteoconductivity, osteoinductivity and antibacterial properties (Figure 7). 
Table 3. The biological performance of different methods for Ta modification.

\section{Surface Modification}

In Vitro Test Results

Mineralization in SBF

- Abundant mineral deposition could be formed in 1 week.

\section{Hydrophilicity}

- After being soaked in SBF for 1 day, the hydrophilicity of the two coatings was improved.

ACP nanospheres-PLA coating HA nanorods-PLA coating

\section{Protein adsorption and release}

- The two nanostructures possessed satisfactory VEGF-FITC adsorption

- The amount of BSA release from ACP nanospheres-PLA coating was faster and larger.

Cell viability and morphology (MG63 cells)

- The two nano-coatings showed no toxic effects on cells.

- Cells' adhesion, interconnecting and spreading were better than those cultured on unmodified samples.

Mineralization in SBF

- $\quad$ CaP nanospheres coating transformed into HA nanosheet which could continuously accumulate on the surface of $\mathrm{Ta}$.

Hydrophilicity

- $\quad \mathrm{CaP}$ nanosheres-PLA coating showed satisfactory hydrophilicity.

CaP nanospheres-PLA coating

\section{BSA release}

- The transformation from amorphous CaP to HA induced the rapid release of BSA at an early stage.

Cell viability (MG63 cells)

- Cells established fine adhesion to CaP nanosheres-PLA coating.

\section{Subchondral bone defect repair}

- $\quad$ Significant new bone formation could be found in samples modified by two coatings.

- By contrast, new bone tissues were lacking in the

\section{Subchondral bone defect repair}

- The modified porous Ta scaffold effectively repaired the defect after 12 weeks. 
Table 3. Cont.

Cartilage defect restoration (rabbit model)

- Modified porous Ta significantly facilitated cartilage restoration at 4,8 and 16 weeks.

Microscopic and histological analyses

- Modified porous Ta groups facilitated calcium salt deposition, as well as formation and maturity of bone and cartilage tissues.

- $\quad$ Sixteen weeks post-surgery, new bone formation could be found around the modified porous Ta.

- The amount of new bone formation was more than those of unmodified samples.

Push out tests

- The modified groups possessed higher maximum push out force.

Anticorrosion test

- $\mathrm{Ta}_{2} \mathrm{O}_{5}$ nanotube films had excellent biocompatibility and prevented the release of ions.

Contact angle and surface energy

- Wettability and surface energy of Ta were enhanced by $\mathrm{Ta}_{2} \mathrm{O}_{5}$ nanotube films.

- Adsorption of BSA and Fn were significantly more on $\mathrm{Ta}_{2} \mathrm{O}_{5}$ nanotube films than bare surface,

Cell adhesion and proliferation (rBMSCs)

- Adhesion and proliferation of rBMSCs were highly enhanced on $\mathrm{Ta}_{2} \mathrm{O}_{5}$ nanotube films. 
Table 3. Cont.

Osteogenesis-related genes expression

- $\quad$ Levels of Osterix, ALP, Collagen-I and Osteocalcin were significantly high on the $\mathrm{Ta}_{2} \mathrm{O}_{5}$ nanotubes films.

Fluorescence microscopy image

- Cells cultured on $\mathrm{Ta}_{2} \mathrm{O}_{5}$ films presented as polygonal morphology and had more filopodia than those on bare surface.

Cell proliferation and morphology (L929 mouse fibroblasts)

Nanoporous Ta oxide layers

- Nanoporous Ta oxide layers with $25 \mathrm{~nm}$ pore size greatly enhanced adhesion, proliferation and extension of fibroblasts.

Mineralization in SBF

- Substantial mineral deposition can be found on the surface of porous Ta treated with $\mathrm{MAO}$ and $\mathrm{NaOH}$ etching.

Cell proliferation (3T3-E1 cells)

MAO combined with $\mathrm{NaOH}$ treatment

- Cell proliferation on the modified samples was better than the untreated ones at 24,48 and $72 \mathrm{~h}$

Cell morphology

- Cells spread over the surface and migrated into the pores of the modified samples, with increasingly filiform protrusions and calcium crystals presented.

Bone ingrowth (rabbit cranial defect model)

- New bone formation could be found around the modified samples at 4 weeks.

- Bone remolding and neovascularization were also found within the pores.

- The cranial defect could be filled by new bone at 12 weeks

Cytotoxicity and cell adhesion (SaOS-2 cells)

- $\quad$ PHAs coating showed no toxicity to the cells.

PHAs (PHB, PHBV and PHB4HB)-Genta coating
Antibacterial properties (S. aureus and E. coli)

- $\quad$ The concentration of Genta released from PHAs coating effectively inhibited the proliferation of S. aureus and E. coli. 
Table 3. Cont.

Surface Modification In Vitro Test Results In Vivo Test Results

Antibacterial Properties (S. aureus and E. coli)

- The novel $\mathrm{ZnO}$ coating showed a two-stage release pattern and effective antibacterial properties.

$\mathrm{ZnO}$ nanorods - nanoslices

hierarchical structure coating

In vivo Infected Studies (KM mice subcutaneous implantation)

- $\quad$ The $\mathrm{ZnO}$ nanorods-nanoslices coating modified Ta foils had ideal antibacterial performance which could last for over 2 weeks in vivo.

- The ZnO nanorods-nanoslices coating had no toxic effect on cells.

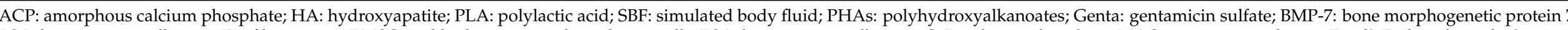

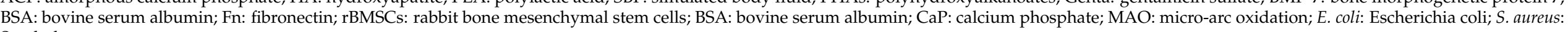
Staphylococcus aureus. 


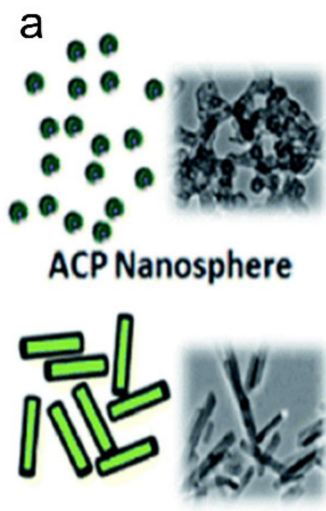

HA Nanorods

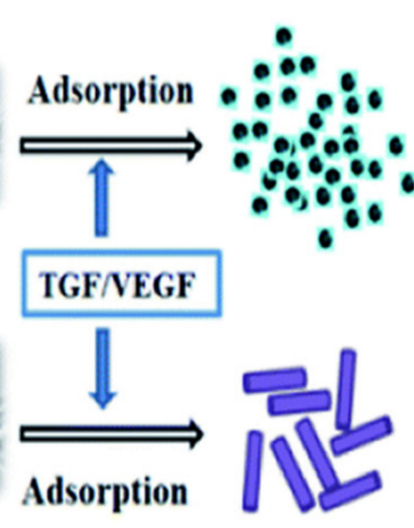

Adsorption
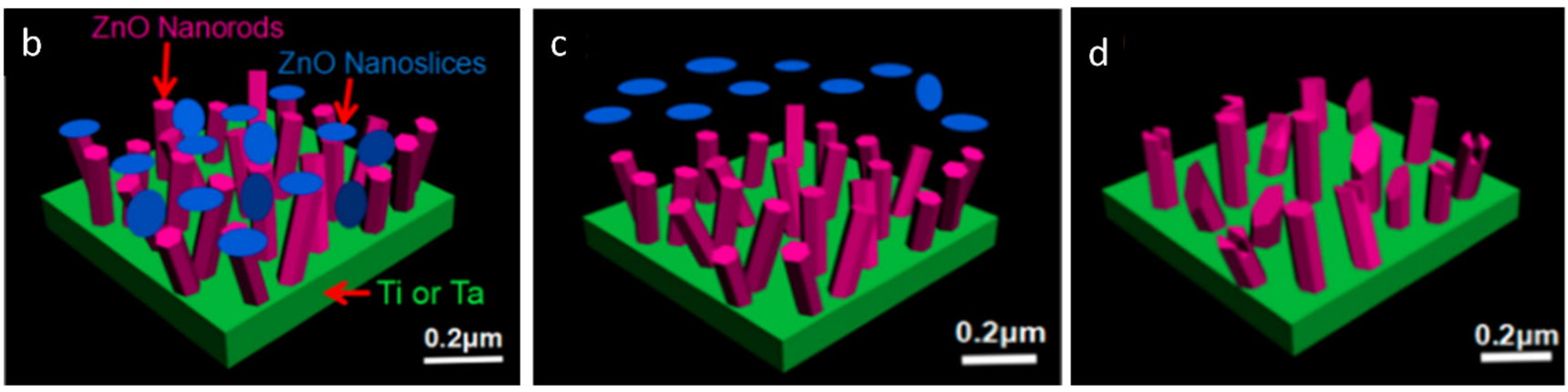

Figure 7. Schematic diagram of the surface modification for porous Ta. Amorphous calcium phosphate (ACP) nanospheres and HA nanorods coating on the surface of Ta scaffold (a). Reprinted from ref. [192]. ZnO nanoslices and ZnO nanorods coating on Ta substrate (b), the $\mathrm{ZnO}$ nanoslices will be released at an early stage-within $48 \mathrm{~h}$ (c), while the $\mathrm{ZnO}$ nanorods are released in a slow pattern over 2 weeks (d). Reprinted with permission from [199]. Copyright (c 2021 by American Chemical Society.

Calcium phosphate (CaP) and hydroxyapatite (HA) are not only the mineral components of human bones, but have also been exploited in porous Ta modification for surface modification and drug delivery [200-202]. Furthermore, the alendronate-CaP coated porous Ta has been verified to fill the bone-implant interface gaps, with an average length of $0.6 \mathrm{~mm}$, in rabbit models after 4 weeks [200]. The mechanism behind this successful restoration of simulated bone defects could be attributed to the slowly released alendronate, which inhibited the activity of osteoclasts but enhanced that of osteoblasts at the same time. Similarly, the zoledronic acid-HA coated porous Ta rod also gained significantly more bone formation both at the peri-implant area and within the inner space compared with the unmodified porous Ta groups in canine models [201]. Zhou et al. introduced amorphous calcium phosphate (ACP) nanosphere and HA nanorod coating to modify porous Ta [192]. When immersed in SBF, the two nanostructures showed rapid mineralization on their surface and the mineral deposition increasingly accumulated within 1 week. Simultaneously, the hydrophilicity of two structures was also significantly improved due to the capillary effects. The ACP nanospheres were observed to transform into HA nanosheets in a rapid pace after being soaked in SBF, and this transformation promised rapid mineralization, improved wettability and faster protein release rates [192,193]. In vivo, both kinds of modified porous Ta scaffolds repaired the subchondral bone defects with substantial new bone formation, indicating a promising clinical prospect for bone defect restoration.

Bone morphogenetic protein 7 (BMP-7) has been applied in bone and cartilage repair since 2001 due to its powerful osteoinductivity [203-205]. BMP-7 can act as a bone stimulating agent that induces differentiation of mesenchymal stem cells into osteoblasts and 
chondroblasts [206]. By soaking porous Ta in the solution of BMP-7, Wang et al. [194] coated BMP-7 on the surface of porous Ta rods. Subsequently, the BMP-7 modified porous Ta rods obtained satisfactory results of subchondral bone and cartilage repairing in rabbit models with substantial chondroid-like tissues recovering in the defect areas within 16 weeks. Furthermore, bone ingrowth depth was found to be $0.2-1.2 \mathrm{~mm}$ in the modified samples, which finally resulted in rigid bone-implant interlocking.

Fabrication of $\mathrm{Ta}_{2} \mathrm{O}_{5}$ nanotube layers on the surface by anodization [195,196] or micro-arc oxidation (MAO) [207] is another approach to ameliorate the bioactivity of Ta. With the formation of nanotubes, the $\mathrm{Ca}$ and $\mathrm{P}$ elements contained in electrolytes can be incorporated into the oxide nanotubes by either of the aforementioned methods [208]. However, MAO may result in toxic effects on cell viability due to the by-products, i.e., reactive oxygen species (ROS) and reactive nitrogen species (RNS). Combined with alkali pretreatment, these toxic elements produced by the process of MAO were dissolved and the newly formed sodium tantalate layer and could further facilitate the deposition of apatite in SBF. It is well defined that the substantial apatite layer formed on the surface of implants is the prerequisite for bone-implant integration [19,197]. In this regard, the combination of MAO and alkali treatment will be an effective way to modify porous Ta to boost its osteoconductivity.

Implant-associated infection has long been a thorny problem in clinical settings, which always results in catastrophic failure and additional expenditure [209,210]. It is imperative to find rational methods to endow porous Ta with antibacterial property. Polyhydroxyalkanoates (PHAs) are biodegradable and biocompatible materials which can be used as natural carrier for drug delivery and scaffold for tissue replacement [211]. Loading PHAs coating containing antibiotics on the surface of porous Ta and obtaining a controlled antibiotics release will be an optimal choice to avoid implant-associated infection [212] Rodríguez-Contreras et al. [198] coated the PHA-Genta composite layer both on the outer and inner surface of porous Ta cervical fusion cages. The continuously released Genta from PHA coating with homogeneous concentration protected these porous Ta cages from infection of $\mathrm{Gram}^{+}$and $\mathrm{Gram}^{-}$bacteria. On the other hand, a $\mathrm{ZnO}$ nanorod-nanoslice hierarchical coating was proposed by Liao et al. [199]. In vitro, the $\mathrm{ZnO}$ nanoslice was first released from the superficial layer to kill bacteria during the early stage, and the antibacterial efficacy lasted for $24 \mathrm{~h}$. By contrast, the release of $\mathrm{ZnO}$ nanorod showed a slow but stable pattern. Therefore, the combined $\mathrm{ZnO}$ nanorod-nanoslice coating possessed a two-stage release pattern and could last for over 2 weeks in vivo, avoiding the implant-associated infection which commonly occurred within 1 week post-surgery [199].

\section{Conclusions}

Owing to its excellent biological and mechanical properties, porous Ta is an optimal biomaterial for bone tissue engineering and has gained satisfactory clinical results, though modifications are needed to refine it. With the advent of additive manufacturing, the printed porous Ta has shed light on the design and manufacture of novel porous Ta-based implants for individualized healthcare as the macrostructure, pore size, pore geometry and porosity of porous Ta implants can be adjusted to meet the needs of the host, especially when huge and complex bone defects are present at the load-bearing parts. Moreover, various modification methods have been emerged to enhance the bioactivity and antibacterial activity of porous Ta. In addition, the modified porous Ta will definitely be used to cope with various pathological conditions, e.g., osteoporosis, infection, diabetes and even tumors. However, in-depth studies are still desired to explore the potential development of porous Ta. Firstly, the impact of the topological structure on the biological and mechanical properties of porous $\mathrm{Ti}$ or Ti alloy has been fully detected, but the relative research on porous $\mathrm{Ta}$ is rare. Since Ta has entirely different characteristics compared with $\mathrm{Ti}$ or $\mathrm{Ti}$ alloy, porous Ta scaffolds with different topological macro- or micro-structures should be determined to verify their biological and mechanical properties and for further application in different biological and mechanical environments. Secondly, abundant randomized con- 
trolled clinical trials (RCT) with sufficient samples and long-term follow-up are still desired to further verify the clinical practicability of modified porous Ta implants. At present, the clinical application of additive manufactured porous Ta implants is mainly confined by the high price of printing individual porous Ta implants. With the development of additive manufacturing technology and the expansion of the additive manufacturing market size, the price of printed porous Ta will decrease sooner or later, and the extensive application of printed porous Ta implants is thus on the horizon, given that the prevalence of aging populations entails increases in orthopaedic arthroplasty and dental implantology.

Author Contributions: Literature search and data analysis, G.H.; writing—original draft preparation, G.H.; writing-review and editing, S.-T.P.; supervision, J.-X.Q. All authors have read and agreed to the published version of the manuscript.

Funding: The National Natural Science Foundation of China (81860477; 81860480), Jiangxi Provincial Key R\&D Plan (20181ACG70009), the Youth Science Fund Project of the Jiangxi Provincial Science and Technology Department (20181BAB215022), and the Young Teachers Research and Development Fund Project of Nanchang University (4209-16100009-PY201818) financially supported this work and its publication costs.

Institutional Review Board Statement: Not applicable.

Informed Consent Statement: Not applicable.

Data Availability Statement: No new data were created or analyzed in this study.

Conflicts of Interest: The authors declare no conflict of interest.

\section{References}

1. Weeks, M.E. The discovery of the elements. VII. Columbium, tantalum, and vanadium. J. Chem. Educ. 1932, 9, 863. [CrossRef]

2. Fuerst, J.; Medlin, D.; Carter, M.; Sears, J.; Vander Voort, G. LASER Additive Manufacturing of Titanium-Tantalum Alloy Structured Interfaces for Modular Orthopedic Devices. JOM 2015, 67, 775-780. [CrossRef]

3. Thijs, L.; Montero Sistiaga, M.L.; Wauthle, R.; Xie, Q.; Kruth, J.-P.; Van Humbeeck, J. Strong morphological and crystallographic texture and resulting yield strength anisotropy in selective laser melted tantalum. Acta Mater. 2013, 61, 4657-4668. [CrossRef]

4. Zhou, L.; Yuan, T.; Li, R.; Tang, J.; Wang, G.; Guo, K. Selective laser melting of pure tantalum: Densification, microstructure and mechanical behaviors. Mater. Sci. Eng. A 2017, 707, 443-451. [CrossRef]

5. Black, J. Biological performance of tantalum. Clin. Mater. 1994, 16, 167-173. [CrossRef]

6. Wang, F.; Li, C.; Zhang, S.; Liu, H. Tantalum coated on titanium dioxide nanotubes by plasma spraying enhances cytocompatibility for dental implants. Surf. Coat. Technol. 2020, 382, 125161. [CrossRef]

7. Zhang, X.M.; Li, Y.; Gu, Y.X.; Zhang, C.N.; Lai, H.C.; Shi, J.Y. Ta-Coated Titanium Surface with Superior Bacteriostasis and Osseointegration. Int. J. Nanomedicine 2019, 14, 8693-8706. [CrossRef]

8. Lu, R.J.; Wang, X.; He, H.X.; E, L.L.; Li, Y.; Zhang, G.L.; Li, C.J.; Ning, C.Y.; Liu, H.C. Tantalum-incorporated hydroxyapatite coating on titanium implants: Its mechanical and in vitro osteogenic properties. J. Mater. Sci. Mater. Med. 2019, 30, 111. [CrossRef]

9. Rahmati, B.; Sarhan, A.A.D.; Basirun, W.J.; Abas, W.A.B.W. Ceramic tantalum oxide thin film coating to enhance the corrosion and wear characteristics of Ti 6Al 4V alloy. J. Alloys Compd. 2016, 676, 369-376. [CrossRef]

10. Zhu, H.; Ji, X.; Guan, H.; Zhao, L.; Zhao, L.; Liu, C.; Cai, C.; Li, W.; Tao, T.; Reseland, J.E.; et al. Tantalum nanoparticles reinforced polyetheretherketone shows enhanced bone formation. Mater. Sci. Eng. C Mater. Biol. Appl. 2019, 101, 232-242. [CrossRef]

11. Singh, B.; Singh, G.; Sidhu, B.S. In vitro investigation of $\mathrm{Nb}$ Ta alloy coating deposited on CoCr alloy for biomedical implants. Surf. Coat. Technol. 2019, 377. [CrossRef]

12. Skoog, S.A.; Kumar, G.; Goering, P.L.; Williams, B.; Stiglich, J.; Narayan, R.J. Biological Response of Human Bone Marrow-Derived Mesenchymal Stem Cells to Commercial Tantalum Coatings with Microscale and Nanoscale Surface Topographies. JOM 2016, 68, 1672-1678. [CrossRef]

13. Jin, W.; Wang, G.; Peng, X.; Li, W.; Qasim, A.M.; Chu, P.K. Tantalum nitride films for corrosion protection of biomedical Mg-Y-RE alloy. J. Alloys Compd. 2018, 764, 947-958. [CrossRef]

14. Wang, H.; Zheng, Y.; Jiang, C.; Li, Y.; Fu, Y. In vitro corrosion behavior and cytocompatibility of pure Fe implanted with Ta. Surf. Coat. Technol. 2017, 320, 201-205. [CrossRef]

15. Moreira, H.; Costa-Barbosa, A.; Marques, S.M.; Sampaio, P.; Carvalho, S. Evaluation of cell activation promoted by tantalum and tantalum oxide coatings deposited by reactive DC magnetron sputtering. Surf. Coat. Technol. 2017, 330, 260-269. [CrossRef]

16. Harrison, P.L.; Harrison, T.; Stockley, I.; Smith, T.J. Does tantalum exhibit any intrinsic antimicrobial or antibiofilm properties? Bone Joint J. 2017, 99B, 1153-1156.

17. Schildhauer, T.A.; Robie, B.; Muhr, G.; Koller, M. Bacterial adherence to tantalum versus commonly used orthopedic metallic implant materials. J. Orthop. Trauma 2006, 20, 476-484. [CrossRef] 
18. Shimabukuro, M.; Ito, H.; Tsutsumi, Y.; Nozaki, K.; Chen, P.; Yamada, R.; Ashida, M.; Nagai, A.; Hanawa, T. The Effects of Various Metallic Surfaces on Cellular and Bacterial Adhesion. Metals 2019, 9, 1145. [CrossRef]

19. Miyazaki, T.; Kim, H.-M.; Kokubo, T.; Ohtsuki, C.; Kato, H.; Nakamura, T. Mechanism of bonelike apatite formation on bioactive tantalum metal in a simulated body fluid. Biomaterials 2002, 23, 827-832. [CrossRef]

20. Levine, B.R.; Sporer, S.; Poggie, R.A.; Della Valle, C.J.; Jacobs, J.J. Experimental and clinical performance of porous tantalum in orthopedic surgery. Biomaterials 2006, 27, 4671-4681. [CrossRef]

21. Kang, C.; Wei, L.; Song, B.; Chen, L.; Liu, J.; Deng, B.; Pan, X.; Shao, L. Involvement of autophagy in tantalum nanoparticle-induced osteoblast proliferation. Int. J. Nanomedicine 2017, 12, 4323-4333. [CrossRef] [PubMed]

22. Shi, L.Y.; Wang, A.; Zang, F.Z.; Wang, J.X.; Pan, X.W.; Chen, H.J. Tantalum-coated pedicle screws enhance implant integration. Colloids Surf. B Biointerfaces 2017, 160, 22-32. [CrossRef]

23. Lu, M.M.; Wu, P.S.; Guo, X.J.; Yin, L.L.; Cao, H.L.; Zou, D. Osteoinductive effects of tantalum and titanium on bone mesenchymal stromal cells and bone formation in ovariectomized rats. Eur. Rev. Med. Pharmacol. Sci. 2018, 22, 7087-7104. [PubMed]

24. Duan, P.; Bonewald, L.F. The role of the wnt/beta-catenin signaling pathway in formation and maintenance of bone and teeth. Int. J. Biochem. Cell Biol. 2016, 77, 23-29. [CrossRef] [PubMed]

25. Lu, M.; Zhuang, X.; Tang, K.; Wu, P.; Guo, X.; Yin, L.; Cao, H.; Zou, D. Intrinsic Surface Effects of Tantalum and Titanium on Integrin alpha5beta1/ ERK1/2 Pathway-Mediated Osteogenic Differentiation in Rat Bone Mesenchymal Stromal Cells. Cell. Physiol. Biochem. 2018, 51, 589-609. [CrossRef]

26. Qian, H.; Lei, T.; Ye, Z.; Hu, Y.; Lei, P. From the Performance to the Essence: The Biological Mechanisms of How Tantalum Contributes to Osteogenesis. Biomed. Res. Int. 2020, 2020, 5162524. [CrossRef]

27. Dou, X.; Wei, X.; Liu, G.; Wang, S.; Lv, Y.; Li, J.; Ma, Z.; Zheng, G.; Wang, Y.; Hu, M.; et al. Effect of porous tantalum on promoting the osteogenic differentiation of bone marrow mesenchymal stem cells in vitro through the MAPK/ERK signal pathway. J. Orthop. Translat. 2019, 19, 81-93. [CrossRef] [PubMed]

28. Wang, L.; Hu, X.; Ma, X.; Ma, Z.; Zhang, Y.; Lu, Y.; Li, X.; Lei, W.; Feng, Y. Promotion of osteointegration under diabetic conditions by tantalum coating-based surface modification on 3-dimensional printed porous titanium implants. Colloids Surf. B Biointerfaces 2016, 148, 440-452. [CrossRef]

29. Van Bael, S.; Chai, Y.C.; Truscello, S.; Moesen, M.; Kerckhofs, G.; Van Oosterwyck, H.; Kruth, J.P.; Schrooten, J. The effect of pore geometry on the in vitro biological behavior of human periosteum-derived cells seeded on selective laser-melted Ti6Al4V bone scaffolds. Acta Biomater. 2012, 8, 2824-2834. [CrossRef]

30. Van der Stok, J.; Van der Jagt, O.P.; Amin Yavari, S.; De Haas, M.F.; Waarsing, J.H.; Jahr, H.; Van Lieshout, E.M.; Patka, P.; Verhaar, J.A.; Zadpoor, A.A.; et al. Selective laser melting-produced porous titanium scaffolds regenerate bone in critical size cortical bone defects. J. Orthop. Res. 2013, 31, 792-799. [CrossRef]

31. Bobbert, F.S.L.; Zadpoor, A.A. Effects of bone substitute architecture and surface properties on cell response, angiogenesis, and structure of new bone. J. Mater. Chem. B 2017, 5, 6175-6192. [CrossRef]

32. Arabnejad, S.; Burnett Johnston, R.; Pura, J.A.; Singh, B.; Tanzer, M.; Pasini, D. High-strength porous biomaterials for bone replacement: A strategy to assess the interplay between cell morphology, mechanical properties, bone ingrowth and manufacturing constraints. Acta Biomater. 2016, 30, 345-356. [CrossRef] [PubMed]

33. Zardiackas, L.D.; Parsell, D.E.; Dillon, L.D.; Mitchell, D.W.; Nunnery, L.A.; Poggie, R. Structure, metallurgy, and mechanical properties of a porous tantalum foam. J. Biomed. Mater. Res. 2001, 58, 180-187. [CrossRef]

34. Sinclair, S.K.; Konz, G.J.; Dawson, J.M.; Epperson, R.T.; Bloebaum, R.D. Host bone response to polyetheretherketone versus porous tantalum implants for cervical spinal fusion in a goat model. Spine 2012, 37, 571-580. [CrossRef] [PubMed]

35. Gruen, T.A.; Poggie, R.A.; Lewallen, D.G.; Hanssen, A.D.; Lewis, R.J.; O’Keefe, T.J.; Stulberg, S.D.; Sutherland, C.J. Radiographic evaluation of a monoblock acetabular component: A multicenter study with 2- to 5-year results. J. Arthroplasty 2005, 20, 369-378. [CrossRef]

36. Piglionico, S.; Bousquet, J.; Fatima, N.; Renaud, M.; Collart-Dutilleul, P.Y.; Bousquet, P. Porous Tantalum VS. Titanium Implants: Enhanced Mineralized Matrix Formation after Stem Cells Proliferation and Differentiation. J. Clin. Med. 2020, 9, 3657. [CrossRef]

37. Bobyn, J.D.; Toh, K.K.; Hacking, S.A.; Tanzer, M.; Krygier, J.J. Tissue response to porous tantalum acetabular cups: A canine model. J. Arthroplasty 1999, 14, 347-354. [CrossRef]

38. Bobyn, J.D.; Stackpool, G.J.; Hacking, S.A.; Tanzer, M.; Krygier, J.J. Characteristics of bone ingrowth and interface mechanics of a new porous tantalum biomaterial. J. Bone Joint Surg. Br. 1999, 81, 907-914. [CrossRef]

39. Gordon, W.J.; Conzemius, M.G.; Birdsall, E.; Wannemuehler, Y.; Mallapragada, S.; Lewallen, D.G.; Yaszemski, M.J.; O’Driscoll, S.W. Chondroconductive potential of tantalum trabecular metal. J. Biomed. Mater. Res. B Appl. Biomater. 2005, 75, 229-233. [CrossRef]

40. Hacking, S.A.; Bobyn, J.D.; Toh, K.; Tanzer, M.; Krygier, J.J. Fibrous tissue ingrowth and attachment to porous tantalum. J. Biomed. Mater. Res. 2000, 52, 631-638. [CrossRef]

41. Reach, J.S., Jr.; Dickey, I.D.; Zobitz, M.E.; Adams, J.E.; Scully, S.P.; Lewallen, D.G. Direct tendon attachment and healing to porous tantalum: An experimental animal study. J. Bone Joint Surg. Am. 2007, 89, 1000-1009.

42. Zhang, Y.; Ahn, P.B.; Fitzpatrick, D.C.; Heiner, A.D.; Poggie, R.A.; Brown, T.D. Interfacial Frictional Behavior: Cancellous Bone, Cortical Bone, and a Novel Porous Tantalum Biomaterial. J. Musculoskelet. Res. 2011, 3, 245-251. [CrossRef] 
43. Mandal, B.B.; Kundu, S.C. Cell proliferation and migration in silk fibroin 3D scaffolds. Biomaterials 2009, 30, 2956-2965. [CrossRef] [PubMed]

44. Sagomonyants, K.B.; Hakim-Zargar, M.; Jhaveri, A.; Aronow, M.S.; Gronowicz, G. Porous tantalum stimulates the proliferation and osteogenesis of osteoblasts from elderly female patients. J. Orthop. Res. 2011, 29, 609-616. [CrossRef] [PubMed]

45. Levine, B.; Della Valle, C.J.; Jacobs, J.J. Applications of porous tantalum in total hip arthroplasty. J. Am. Acad. Orthop. Surg. 2006, 14, 646-655. [CrossRef] [PubMed]

46. Harrison, A.K.; Gioe, T.J.; Simonelli, C.; Tatman, P.J.; Schoeller, M.C. Do porous tantalum implants help preserve bone?: Evaluation of tibial bone density surrounding tantalum tibial implants in TKA. Clin. Orthop. Relat. Res. 2010, 468, 2739-2745. [CrossRef] [PubMed]

47. Wang, X.; Xu, S.; Zhou, S.; Xu, W.; Leary, M.; Choong, P.; Qian, M.; Brandt, M.; Xie, Y.M. Topological design and additive manufacturing of porous metals for bone scaffolds and orthopaedic implants: A review. Biomaterials 2016, 83, 127-141. [CrossRef]

48. Wei, X.; Zhao, D.; Wang, B.; Wang, W.; Kang, K.; Xie, H.; Liu, B.; Zhang, X.; Zhang, J.; Yang, Z. Tantalum coating of porous carbon scaffold supplemented with autologous bone marrow stromal stem cells for bone regeneration in vitro and in vivo. Exp. Biol. Med. 2016, 241, 592-602. [CrossRef]

49. Wang, Q.; Zhang, H.; Li, Q.; Ye, L.; Gan, H.; Liu, Y.; Wang, H.; Wang, Z. Biocompatibility and osteogenic properties of porous tantalum. Exp. Ther Med. 2015, 9, 780-786. [CrossRef]

50. Zhou, Y.; Zhu, Y. Three-dimensional Ta foams produced by replication of NaCl space-holders. Mater. Lett. 2013, 99, 8-10. [CrossRef]

51. Balla, V.K.; Bodhak, S.; Bose, S.; Bandyopadhyay, A. Porous tantalum structures for bone implants: Fabrication, mechanical and in vitro biological properties. Acta Biomater. 2010, 6, 3349-3359. [CrossRef]

52. Wauthle, R.; van der Stok, J.; Amin Yavari, S.; Van Humbeeck, J.; Kruth, J.P.; Zadpoor, A.A.; Weinans, H.; Mulier, M.; Schrooten, J. Additively manufactured porous tantalum implants. Acta Biomater. 2015, 14, 217-225. [CrossRef]

53. Tang, H.P.; Yang, K.; Jia, L.; He, W.W.; Yang, L.; Zhang, X.Z. Tantalum Bone Implants Printed by Selective Electron Beam Manufacturing (SEBM) and Their Clinical Applications. JOM 2020, 72, 1016-1021. [CrossRef]

54. Wang, H.; Su, K.; Su, L.; Liang, P.; Ji, P.; Wang, C. Comparison of 3D-printed porous tantalum and titanium scaffolds on osteointegration and osteogenesis. Mater. Sci. Eng. C Mater. Biol. Appl. 2019, 104, 109908. [CrossRef]

55. Guo, Y.; Xie, K.; Jiang, W.; Wang, L.; Li, G.; Zhao, S.; Wu, W.; Hao, Y. In Vitro and in Vivo Study of 3D-Printed Porous Tantalum Scaffolds for Repairing Bone Defects. ACS Biomater. Sci. Eng. 2018, 5, 1123-1133. [CrossRef]

56. Qian, H.; Lei, T.; Lei, P.; Hu, Y. Additively Manufactured Tantalum Implants for Repairing Bone Defects: A Systematic Review. Tissue Eng. Part. B. Rev. 2021, 27, 166-180. [CrossRef]

57. Butler, J.S.; Lui, D.F.; Malhotra, K.; Suarez-Huerta, M.L.; Yu, H.; Selvadurai, S.; Agu, O.; Molloy, S. 360-Degree Complex Primary Reconstruction Using Porous Tantalum Cages for Adult Degenerative Spinal Deformity. Global Spine J. 2019, 9, 613-618. [CrossRef]

58. Pakos, E.E.; Megas, P.; Paschos, N.K.; Syggelos, S.A.; Kouzelis, A.; Georgiadis, G.; Xenakis, T.A. Modified porous tantalum rod technique for the treatment of femoral head osteonecrosis. World J. Orthop. 2015, 6, 829-837. [CrossRef] [PubMed]

59. Witek, L.; Alifarag, A.M.; Tovar, N.; Lopez, C.D.; Gil, L.F.; Gorbonosov, M.; Hannan, K.; Neiva, R.; Coelho, P.G. Osteogenic parameters surrounding trabecular tantalum metal implants in osteotomies prepared via osseodensification drilling. Medicina Oral, Patologia Oral y Cirugia Bucal 2019, 24, e764-e769. [CrossRef]

60. Simon, S.; Frank, B.J.H.; Aichmair, A.; Dominkus, M.; Hofstaetter, J.G. Reconstruction of Proximal Metaphyseal Femoral Defects Using Trabecular Metal Augments in Revision Total Hip Arthroplasty. Arthroplast. Today 2021, 8, 216-221. [CrossRef]

61. Liu, F.; Wang, W.; Yang, L.; Wang, B.; Wang, J.; Chai, W.; Zhao, D. An epidemiological study of etiology and clinical characteristics in patients with nontraumatic osteonecrosis of the femoral head. J. Res. Med. Sci 2017, 22, 15. [CrossRef]

62. Ikeuchi, K.; Hasegawa, Y.; Seki, T.; Takegami, Y.; Amano, T.; Ishiguro, N. Epidemiology of nontraumatic osteonecrosis of the femoral head in Japan. Mod. Rheumatol. 2015, 25, 278-281. [CrossRef] [PubMed]

63. Scully, S.P.; Aaron, R.K.; Urbaniak, J.R. Survival analysis of hips treated with core decompression or vascularized fibular grafting because of avascular necrosis. J. Bone Joint Surg. Am. 1998, 80, 1270-1275. [CrossRef]

64. Gonzalez del Pino, J.; Knapp, K.; Gomez Castresana, F.; Benito, M. Revascularization of femoral head ischemic necrosis with vascularized bone graft: A CT scan experimental study. Skeletal Radiol. 1990, 19, 197-202. [CrossRef] [PubMed]

65. Tsao, A.K.; Roberson, J.R.; Christie, M.J.; Dore, D.D.; Heck, D.A.; Robertson, D.D.; Poggie, R.A. Biomechanical and clinical evaluations of a porous tantalum implant for the treatment of early-stage osteonecrosis. J. Bone Joint Surg. Am. 2005, 87 (Suppl. 2), 22-27. [PubMed]

66. Veillette, C.J.; Mehdian, H.; Schemitsch, E.H.; McKee, M.D. Survivorship analysis and radiographic outcome following tantalum rod insertion for osteonecrosis of the femoral head. J. Bone Joint Surg. Am. 2006, 88 (Suppl. 3), 48-55. [PubMed]

67. Shuler, M.S.; Rooks, M.D.; Roberson, J.R. Porous tantalum implant in early osteonecrosis of the hip: Preliminary report on operative, survival, and outcomes results. J. Arthroplasty 2007, 22, 26-31. [CrossRef]

68. Liu, G.; Wang, J.; Yang, S.; Xu, W.; Ye, S.; Xia, T. Effect of a porous tantalum rod on early and intermediate stages of necrosis of the femoral head. Biomed. Mater. 2010, 5, 065003. [CrossRef]

69. Zhang, X.; Wang, J.; Xiao, J.; Shi, Z. Early failures of porous tantalum osteonecrosis implants: A case series with retrieval analysis. Int. Orthop. 2016, 40, 1827-1834. [CrossRef] 
70. Papapietro, N.; Di Martino, A.; Niccoli, G.; Palumbo, A.; Salvatore, G.; Forriol, F.; Denaro, V. Trabecular metal screw implanted for avascular necrosis of the femoral head may complicate subsequent arthroplasty surgery. Eur. J. Orthop. Surg. Traumatol. 2014, 24, 931-938. [CrossRef]

71. Liu, Y.; Su, X.; Zhou, S.; Wang, L.; Wang, C.; Liu, S. A modified porous tantalum implant technique for osteonecrosis of the femoral head: Survivorship analysis and prognostic factors for radiographic progression and conversion to total hip arthroplasty. Int. J. Clin. Exp. Med. 2015, 8, 1918-1930. [PubMed]

72. Liu, Z.H.; Guo, W.S.; Li, Z.R.; Cheng, L.M.; Zhang, Q.D.; Yue, D.B.; Shi, Z.C.; Wang, B.L.; Sun, W.; Zhang, N.F. Porous tantalum rods for treating osteonecrosis of the femoral head. Genet. Mol. Res. 2014, 13, 8342-8352. [CrossRef] [PubMed]

73. Ma, J.; Sun, W.; Gao, F.; Guo, W.; Wang, Y.; Li, Z. Porous Tantalum Implant in Treating Osteonecrosis of the Femoral Head: Still a Viable Option? Sci Rep. 2016, 6, 28227. [CrossRef]

74. Tanzer, M.; Bobyn, J.D.; Krygier, J.J.; Karabasz, D. Histopathologic retrieval analysis of clinically failed porous tantalum osteonecrosis implants. J. Bone Joint Surg. Am. 2008, 90, 1282-1289. [CrossRef]

75. Varitimidis, S.E.; Dimitroulias, A.P.; Karachalios, T.S.; Dailiana, Z.H.; Malizos, K.N. Outcome after tantalum rod implantation for treatment of femoral head osteonecrosis: 26 hips followed for an average of 3 years. Acta Orthop. 2009, 80, 20-25. [CrossRef]

76. Zhao, D.; Zhang, Y.; Wang, W.; Liu, Y.; Li, Z.; Wang, B.; Yu, X. Tantalum rod implantation and vascularized iliac grafting for osteonecrosis of the femoral head. Orthopedics 2013, 36, 789-795. [CrossRef]

77. Zhao, D.; Liu, B.; Wang, B.; Yang, L.; Xie, H.; Huang, S.; Zhang, Y.; Wei, X. Autologous bone marrow mesenchymal stem cells associated with tantalum rod implantation and vascularized iliac grafting for the treatment of end-stage osteonecrosis of the femoral head. Biomed. Res. Int. 2015, 2015, 240506. [CrossRef]

78. Sculco, T.P. The acetabular component: An elliptical monoblock alternative. J. Arthroplasty 2002, 17, 118-120. [CrossRef]

79. Meneghini, R.M.; Ford, K.S.; McCollough, C.H.; Hanssen, A.D.; Lewallen, D.G. Bone remodeling around porous metal cementless acetabular components. J. Arthroplasty 2010, 25, 741-747. [CrossRef]

80. Jasty, M.; Bragdon, C.R.; Haire, T.; Mulroy, R.D., Jr.; Harris, W.H. Comparison of bone ingrowth into cobalt chrome sphere and titanium fiber mesh porous coated cementless canine acetabular components. J. Biomed. Mater. Res. 1993, 27, 639-644. [CrossRef]

81. Macheras, G.; Kateros, K.; Kostakos, A.; Koutsostathis, S.; Danomaras, D.; Papagelopoulos, P.J. Eight- to ten-year clinical and radiographic outcome of a porous tantalum monoblock acetabular component. J. Arthroplasty 2009, 24, 705-709. [CrossRef]

82. Garbuz, D.S. Revision total hip: A novel modular cementless acetabular system for reconstruction of severe acetabular bone loss. Oper. Tech. Orthop. 2004, 14, 117-120. [CrossRef]

83. Van Kleunen, J.P.; Lee, G.C.; Lementowski, P.W.; Nelson, C.L.; Garino, J.P. Acetabular revisions using trabecular metal cups and augments. J. Arthroplasty 2009, 24, 64-68. [CrossRef]

84. Sporer, S.M.; Paprosky, W.G. The use of a trabecular metal acetabular component and trabecular metal augment for severe acetabular defects. J. Arthroplasty 2006, 21, 83-86. [CrossRef]

85. Sporer, S.M.; Paprosky, W.G. Acetabular revision using a trabecular metal acetabular component for severe acetabular bone loss associated with a pelvic discontinuity. J. Arthroplasty 2006, 21, 87-90. [CrossRef]

86. Siegmeth, A.; Duncan, C.P.; Masri, B.A.; Kim, W.Y.; Garbuz, D.S. Modular tantalum augments for acetabular defects in revision hip arthroplasty. Clin. Orthop. Relat. Res. 2009, 467, 199-205. [CrossRef]

87. Malkani, A.L.; Price, M.R.; Crawford, C.H., 3rd; Baker, D.L. Acetabular component revision using a porous tantalum biomaterial: A case series. J. Arthroplasty 2009, 24, 1068-1073. [CrossRef]

88. Issack, P.S. Use of porous tantalum for acetabular reconstruction in revision hip arthroplasty. J. Bone Joint Surg. Am. 2013, 95, 1981-1987. [CrossRef]

89. Nehme, A.; Lewallen, D.G.; Hanssen, A.D. Modular porous metal augments for treatment of severe acetabular bone loss during revision hip arthroplasty. Clin. Orthop. Relat. Res. 2004, 429, 201-208. [CrossRef]

90. Unger, A.S.; Lewis, R.J.; Gruen, T. Evaluation of a porous tantalum uncemented acetabular cup in revision total hip arthroplasty: Clinical and radiological results of 60 hips. J. Arthroplasty 2005, 20, 1002-1009. [CrossRef]

91. Weeden, S.H.; Schmidt, R.H. The use of tantalum porous metal implants for Paprosky 3A and 3B defects. J. Arthroplasty 2007, 22, 151-155. [CrossRef] [PubMed]

92. Del Gaizo, D.J.; Kancherla, V.; Sporer, S.M.; Paprosky, W.G. Tantalum augments for Paprosky IIIA defects remain stable at midterm followup. Clin. Orthop. Relat. Res. 2012, 470, 395-401. [CrossRef] [PubMed]

93. Flecher, X.; Appy, B.; Parratte, S.; Ollivier, M.; Argenson, J.N. Use of porous tantalum components in Paprosky two and three acetabular revision. A minimum five-year follow-up of fifty one hips. Int. Orthop. 2017, 41, 911-916. [CrossRef] [PubMed]

94. Jenkins, D.R.; Odland, A.N.; Sierra, R.J.; Hanssen, A.D.; Lewallen, D.G. Minimum Five-Year Outcomes with Porous Tantalum Acetabular Cup and Augment Construct in Complex Revision Total Hip Arthroplasty. J. Bone Joint Surg. Am. 2017, 99, e49. [CrossRef]

95. Lochel, J.; Janz, V.; Hipfl, C.; Perka, C.; Wassilew, G.I. Reconstruction of acetabular defects with porous tantalum shells and augments in revision total hip arthroplasty at ten-year follow-up. Bone Joint J. 2019, 101-B, 311-316. [CrossRef]

96. Brown, T.S.; Salib, C.G.; Rose, P.S.; Sim, F.H.; Lewallen, D.G.; Abdel, M.P. Reconstruction of the hip after resection of periacetabular oncological lesions: A systematic review. Bone Joint J. 2018, 100-B, 22-30. [CrossRef]

97. Rose, P.S.; Halasy, M.; Trousdale, R.T.; Hanssen, A.D.; Sim, F.H.; Berry, D.J.; Lewallen, D.G. Preliminary results of tantalum acetabular components for THA after pelvic radiation. Clin. Orthop. Relat. Res. 2006, 453, 195-198. [CrossRef] 
98. Joglekar, S.B.; Rose, P.S.; Lewallen, D.G.; Sim, F.H. Tantalum acetabular cups provide secure fixation in THA after pelvic irradiation at minimum 5-year followup. Clin. Orthop. Relat. Res. 2012, 470, 3041-3047. [CrossRef]

99. De Paolis, M.; Zucchini, R.; Romagnoli, C.; Romantini, M.; Mariotti, F.; Donati, D.M. Middle term results of tantalum acetabular cups in total hip arthroplasty following pelvic irradiation. Acta Orthop Traumatol. Turc. 2019, 53, 165-169. [CrossRef]

100. Mahoney, C.R.; Garvin, K.L. Periprosthetic acetabular stress fracture causing pelvic discontinuity. Orthopedics 2002, 25, 83-85. [CrossRef]

101. Springer, B.D.; Berry, D.J.; Cabanela, M.E.; Hanssen, A.D.; Lewallen, D.G. Early postoperative transverse pelvic fracture: A new complication related to revision arthroplasty with an uncemented cup. J. Bone Joint Surg. Am. 2005, 87, 2626-2631. [PubMed]

102. Levine, B.; Sporer, S.; Della Valle, C.J.; Jacobs, J.J.; Paprosky, W. Porous tantalum in reconstructive surgery of the knee: A review. J. Knee Surg. 2007, 20, 185-194. [CrossRef] [PubMed]

103. Helm, A.T.; Kerin, C.; Ghalayini, S.R.; McLauchlan, G.J. Preliminary results of an uncemented trabecular metal tibial component in total knee arthroplasty. J. Arthroplasty 2009, 24, 941-944. [CrossRef] [PubMed]

104. O'Keefe, T.J.; Winter, S.; Lewallen, D.G.; Robertson, D.D.; Poggie, R.A. Clinical and radiographic evaluation of a monoblock tibial component. J. Arthroplasty 2010, 25, 785-792. [CrossRef]

105. Kamath, A.F.; Lee, G.C.; Sheth, N.P.; Nelson, C.L.; Garino, J.P.; Israelite, C.L. Prospective results of uncemented tantalum monoblock tibia in total knee arthroplasty: Minimum 5-year follow-up in patients younger than 55 years. J. Arthroplasty 2011, 26, 1390-1395. [CrossRef] [PubMed]

106. Unger, A.S.; Duggan, J.P. Midterm results of a porous tantalum monoblock tibia component clinical and radiographic results of 108 knees. J. Arthroplasty 2011, 26, 855-860. [CrossRef] [PubMed]

107. De Martino, I.; D’Apolito, R.; Sculco, P.K.; Poultsides, L.A.; Gasparini, G. Total Knee Arthroplasty Using Cementless Porous Tantalum Monoblock Tibial Component: A Minimum 10-Year Follow-Up. J. Arthroplasty 2016, 31, 2193-2198. [CrossRef]

108. DeFrancesco, C.J.; Canseco, J.A.; Nelson, C.L.; Israelite, C.L.; Kamath, A.F. Uncemented Tantalum Monoblock Tibial Fixation for Total Knee Arthroplasty in Patients Less Than 60 Years of Age: Mean 10-Year Follow-up. J. Bone Joint Surg. Am. 2018, 100, 865-870. [CrossRef]

109. Sambaziotis, C.; Lovy, A.J.; Koller, K.E.; Bloebaum, R.D.; Hirsh, D.M.; Kim, S.J. Histologic retrieval analysis of a porous tantalum metal implant in an infected primary total knee arthroplasty. J. Arthroplasty 2012, 27, 1413-1419. [CrossRef]

110. Meneghini, R.M.; de Beaubien, B.C. Early failure of cementless porous tantalum monoblock tibial components. J. Arthroplasty 2013, 28, 1505-1508. [CrossRef]

111. Long, W.J.; Scuderi, G.R. Porous tantalum cones for large metaphyseal tibial defects in revision total knee arthroplasty: A minimum 2-year follow-up. J. Arthroplasty 2009, 24, 1086-1092. [CrossRef] [PubMed]

112. Potter, G.D., 3rd; Abdel, M.P.; Lewallen, D.G.; Hanssen, A.D. Midterm Results of Porous Tantalum Femoral Cones in Revision Total Knee Arthroplasty. J. Bone Joint Surg. Am. 2016, 98, 1286-1291. [CrossRef] [PubMed]

113. Kamath, A.F.; Lewallen, D.G.; Hanssen, A.D. Porous tantalum metaphyseal cones for severe tibial bone loss in revision knee arthroplasty: A five to nine-year follow-up. J. Bone Joint Surg. Am. 2015, 97, 216-223. [CrossRef]

114. Bohl, D.D.; Brown, N.M.; McDowell, M.A.; Levine, B.R.; Sporer, S.M.; Paprosky, W.G.; Della Valle, C.J. Do Porous Tantalum Metaphyseal Cones Improve Outcomes in Revision Total Knee Arthroplasty? J. Arthroplasty 2018, 33, 171-177. [CrossRef]

115. Nasser, S.; Poggie, R.A. Revision and salvage patellar arthroplasty using a porous tantalum implant. J. Arthroplasty 2004, 19, 562-572. [CrossRef]

116. Ries, M.D.; Cabalo, A.; Bozic, K.J.; Anderson, M. Porous tantalum patellar augmentation: The importance of residual bone stock. Clin. Orthop. Relat. Res. 2006, 452, 166-170. [CrossRef] [PubMed]

117. Kamath, A.F.; Gee, A.O.; Nelson, C.L.; Garino, J.P.; Lotke, P.A.; Lee, G.C. Porous tantalum patellar components in revision total knee arthroplasty minimum 5-year follow-up. J. Arthroplasty 2012, 27, 82-87. [CrossRef]

118. Boileau, P.; Avidor, C.; Krishnan, S.G.; Walch, G.; Kempf, J.F.; Mole, D. Cemented polyethylene versus uncemented metal-backed glenoid components in total shoulder arthroplasty: A prospective, double-blind, randomized study. J. Shoulder Elbow Surg. 2002, 11,351-359. [CrossRef]

119. Edwards, T.B.; Labriola, J.E.; Stanley, R.J.; O'Connor, D.P.; Elkousy, H.A.; Gartsman, G.M. Radiographic comparison of pegged and keeled glenoid components using modern cementing techniques: A prospective randomized study. J. Shoulder Elbow Surg. 2010, 19, 251-257. [CrossRef]

120. Fox, T.J.; Cil, A.; Sperling, J.W.; Sanchez-Sotelo, J.; Schleck, C.D.; Cofield, R.H. Survival of the glenoid component in shoulder arthroplasty. J. Shoulder Elbow Surg. 2009, 18, 859-863. [CrossRef] [PubMed]

121. Walch, G.; Young, A.A.; Melis, B.; Gazielly, D.; Loew, M.; Boileau, P. Results of a convex-back cemented keeled glenoid component in primary osteoarthritis: Multicenter study with a follow-up greater than 5 years. J. Shoulder Elbow Surg. 2011, 20, 385-394. [CrossRef] [PubMed]

122. Fucentese, S.F.; Costouros, J.G.; Kuhnel, S.P.; Gerber, C. Total shoulder arthroplasty with an uncemented soft-metal-backed glenoid component. J. Shoulder Elbow Surg. 2010, 19, 624-631. [CrossRef] [PubMed]

123. Budge, M.D.; Nolan, E.M.; Heisey, M.H.; Baker, K.; Wiater, J.M. Results of total shoulder arthroplasty with a monoblock porous tantalum glenoid component: A prospective minimum 2-year follow-up study. J. Shoulder Elbow Surg. 2013, 22, 535-541. [CrossRef] 
124. Theivendran, K.; Varghese, M.; Large, R.; Bateman, M.; Morgan, M.; Tambe, A.; Espag, M.; Cresswell, T.; Clark, D.I. Reverse total shoulder arthroplasty using a trabecular metal glenoid base plate: Functional and radiological outcomes at two to five years. Bone Joint J. 2016, 98-B, 969-975. [CrossRef]

125. Watson, S.T.; Gudger, G.K., Jr.; Long, C.D.; Tokish, J.M.; Tolan, S.J. Outcomes of Trabecular Metal-backed glenoid components in anatomic total shoulder arthroplasty. J. Shoulder Elbow Surg. 2018, 27, 493-498. [CrossRef] [PubMed]

126. Merolla, G.; Chin, P.; Sasyniuk, T.M.; Paladini, P.; Porcellini, G. Total shoulder arthroplasty with a second-generation tantalum trabecular metal-backed glenoid component: Clinical and radiographic outcomes at a mean follow-up of 38 months. Bone Joint J. 2016, 98-B, 75-80. [CrossRef]

127. Panti, J.P.; Tan, S.; Kuo, W.; Fung, S.; Walker, K.; Duff, J. Clinical and radiologic outcomes of the second-generation Trabecular Metal glenoid for total shoulder replacements after 2-6 years follow-up. Arch. Orthop. Trauma Surg. 2016, 136, 1637-1645. [CrossRef]

128. Wahl, P.; Sprecher, C.M.; Bruning, C.; Meier, C.; Milz, S.; Gautier, E.; Fintan Moriarty, T. Successful bony integration of a porous tantalum implant despite longlasting and ongoing infection: Histologic workup of an explanted shoulder prosthesis. J. Biomed. Mater. Res. B Appl. Biomater. 2018, 106, 2924-2931. [CrossRef]

129. Endrizzi, D.P.; Mackenzie, J.A.; Henry, P.D. Early Debris Formation with a Porous Tantalum Glenoid Component: Radiographic Analysis with 2-Year Minimum Follow-up. J. Bone Joint Surg. Am. 2016, 98, 1023-1029. [CrossRef]

130. Boileau, P.; Krishnan, S.G.; Tinsi, L.; Walch, G.; Coste, J.S.; Mole, D. Tuberosity malposition and migration: Reasons for poor outcomes after hemiarthroplasty for displaced fractures of the proximal humerus. J. Shoulder Elbow Surg. 2002, 11, 401-412. [CrossRef]

131. Li, F.; Jiang, C. Trabecular metal shoulder prosthesis in the treatment of complex proximal humeral fractures. Int. Orthop. 2013, 37, 2259-2264. [CrossRef]

132. Li, F.; Zhu, Y.; Lu, Y.; Liu, X.; Wu, G.; Jiang, C. Hemiarthroplasty for the treatment of complex proximal humeral fractures: Does a trabecular metal prosthesis make a difference? A prospective, comparative study with a minimum 3-year follow-up. J. Shoulder Elbow Surg. 2014, 23, 1437-1443. [CrossRef] [PubMed]

133. Sandow, M.; Schutz, C. Total shoulder arthroplasty using trabecular metal augments to address glenoid retroversion: The preliminary result of 10 patients with minimum 2-year follow-up. J. Shoulder Elbow Surg. 2016, 25, 598-607. [CrossRef] [PubMed]

134. Fernandez-Fairen, M.; Sala, P.; Dufoo, M., Jr.; Ballester, J.; Murcia, A.; Merzthal, L. Anterior cervical fusion with tantalum implant: A prospective randomized controlled study. Spine 2008, 33, 465-472. [CrossRef] [PubMed]

135. Fernandez-Fairen, M.; Alvarado, E.; Torres, A. Eleven-Year Follow-Up of Two Cohorts of Patients Comparing Stand-Alone Porous Tantalum Cage Versus Autologous Bone Graft and Plating in Anterior Cervical Fusions. World Neurosurg 2019, 122, $156-167$. [CrossRef]

136. King, V.; Swart, A.; Winder, M.J. Tantalum trabecular metal implants in anterior cervical corpectomy and fusion: 2-year prospective analysis. J. Clin. Neurosci. 2016, 32, 91-94. [CrossRef]

137. Papacci, F.; Rigante, L.; Fernandez, E.; Meglio, M.; Montano, N. Anterior cervical discectomy and interbody fusion with porous tantalum implant. Results in a series with long-term follow-up. J. Clin. Neurosci. 2016, 33, 159-162. [CrossRef]

138. Mastronardi, L.; Roperto, R.; Cacciotti, G.; Calvosa, F. Anterior Cervical Fusion with Stand-alone Trabecular Metal Cages to Treat Cervical Myelopathy Caused by Degenerative Disk Disease. Observations in 88 Cases with Minimum 12-month Follow-up. J. Neurol. Surg. A Cent. Eur. Neurosurg. 2018, 79, 496-501. [PubMed]

139. Kasliwal, M.K.; Baskin, D.S.; Traynelis, V.C. Failure of porous tantalum cervical interbody fusion devices: Two-year results from a prospective, randomized, multicenter clinical study. J. Spinal Disord. Tech. 2013, 26, 239-245. [CrossRef] [PubMed]

140. Lofgren, H.; Engquist, M.; Hoffmann, P.; Sigstedt, B.; Vavruch, L. Clinical and radiological evaluation of Trabecular Metal and the Smith-Robinson technique in anterior cervical fusion for degenerative disease: A prospective, randomized, controlled study with 2-year follow-up. Eur. Spine J. 2010, 19, 464-473. [CrossRef]

141. Wigfield, C.; Robertson, J.; Gill, S.; Nelson, R. Clinical experience with porous tantalum cervical interbody implants in a prospective randomized controlled trial. Br. J. Neurosurg. 2003, 17, 418-425. [CrossRef] [PubMed]

142. Li, N.; Hu, W.Q.; Xin, W.Q.; Li, Q.F.; Tian, P. Comparison between porous tantalum metal implants and autograft in anterior cervical discectomy and fusion: A meta-analysis. J. Comp. Eff Res. 2019, 8, 511-521. [CrossRef] [PubMed]

143. Wang, Y.; Wei, R.; Subedi, D.; Jiang, H.; Yan, J.; Li, J. Tantalum Fusion Device in Anterior Cervical Discectomy and Fusion For Treatment of Cervical Degeneration Disease: A Systematic Review and Meta-Analysis. Clin. Spine Surg. 2020, 33, 111-119. [CrossRef] [PubMed]

144. Hanc, M.; Fokter, S.K.; Vogrin, M.; Molicnik, A.; Recnik, G. Porous tantalum in spinal surgery: An overview. Eur. J. Orthop. Surg. Traumatol. 2016, 26, 1-7. [CrossRef]

145. Lequin, M.B.; Verbaan, D.; Bouma, G.J. Posterior lumbar interbody fusion with stand-alone Trabecular Metal cages for repeatedly recurrent lumbar disc herniation and back pain. J. Neurosurg. Spine 2014, 20, 617-622. [CrossRef]

146. Lebhar, J.; Kriegel, P.; Chatellier, P.; Breton, Y.; Ropars, M.; Huten, D. Tantalum implants for posterior lumbar interbody fusion: A safe method at medium-term follow-up? Orthop. Traumatol. Surg. Res. 2020, 106, 269-274. [CrossRef]

147. Van de Kelft, E.; Van Goethem, J. Trabecular metal spacers as standalone or with pedicle screw augmentation, in posterior lumbar interbody fusion: A prospective, randomized controlled trial. Eur. Spine J. 2015, 24, 2597-2606. [CrossRef] 
148. Pantalone, A.; Guelfi, M.; Salini, V.; Guelfi, M.G.B. Ankle Arthritis: Etiology and Classifications. In Ankle Joint Arthroscopy; Allegra, F., Cortese, F., Lijoi, F., Eds.; Springer International Publishing: Cham, Switzerland, 2020; pp. 159-163.

149. Adukia, V.; Mangwani, J.; Issac, R.; Hussain, S.; Parker, L. Current concepts in the management of ankle arthritis. J. Clin. Orthop Trauma 2020, 11, 388-398. [CrossRef] [PubMed]

150. Sagherian, B.H.; Claridge, R.J. The Use of Tantalum Metal in Foot and Ankle Surgery. Orthop. Clin. North. Am. 2019, 50, 119-129. [CrossRef]

151. Frigg, A.; Dougall, H.; Boyd, S.; Nigg, B. Can porous tantalum be used to achieve ankle and subtalar arthrodesis?: A pilot study. Clin. Orthop. Relat. Res. 2010, 468, 209-216. [CrossRef]

152. Sagherian, B.H.; Claridge, R.J. Porous tantalum as a structural graft in foot and ankle surgery. Foot Ankle Int. 2012, 33, 179-189. [CrossRef]

153. Bouchard, M.; Barker, L.G.; Claridge, R.J. Technique tip: Tantalum: A structural bone graft option for foot and ankle surgery. Foot Ankle Int. 2004, 25, 39-42. [CrossRef]

154. Economopoulos, K.; Barker, L.; Beauchamp, C.; Claridge, R. Case report: Reconstruction of the distal tibia with porous tantalum spacer after resection for giant cell tumor. Clin. Orthop. Relat. Res. 2010, 468, 1697-1701. [CrossRef] [PubMed]

155. Kreulen, C.; Lian, E.; Giza, E. Technique for Use of Trabecular Metal Spacers in Tibiotalocalcaneal Arthrodesis With Large Bony Defects. Foot Ankle Int. 2017, 38, 96-106. [CrossRef]

156. Boone, D.W. Complications of iliac crest graft and bone grafting alternatives in foot and ankle surgery. Foot Ankle Clin. 2003, 8 , 1-14. [CrossRef]

157. Heary, R.F.; Schlenk, R.P.; Sacchieri, T.A.; Barone, D.; Brotea, C. Persistent iliac crest donor site pain: Independent outcome assessment. Neurosurgery 2002, 50, 510-516; discussion 516-517. [PubMed]

158. Sagherian, B.H.; Claridge, R.J. Salvage of failed total ankle replacement using tantalum trabecular metal: Case series. Foot Ankle Int. 2015, 36, 318-324. [CrossRef] [PubMed]

159. Aubret, S.; Merlini, L.; Fessy, M.; Besse, J.L. Poor outcomes of fusion with Trabecular Metal implants after failed total ankle replacement: Early results in 11 patients. Orthop Traumatol Surg Res. 2018, 104, 231-237. [CrossRef]

160. Sundet, M.; Johnsen, E.; Eikvar, K.H.; Eriksen, M.L. Retrograde nailing, trabecular metal implant and use of bone marrow aspirate concentrate after failed ankle joint replacement. Foot Ankle Surg. 2021, 27, 123-128. [CrossRef]

161. Onggo, J.R.; Nambiar, M.; Phan, K.; Hickey, B.; Galvin, M.; Bedi, H. Outcome after total ankle arthroplasty with a minimum of five years follow-up: A systematic review and meta-analysis. Foot Ankle Surg. 2020, 26, 556-563. [CrossRef]

162. Daniels, T.R.; Younger, A.S.; Penner, M.; Wing, K.; Dryden, P.J.; Wong, H.; Glazebrook, M. Intermediate-term results of total ankle replacement and ankle arthrodesis: A COFAS multicenter study. J. Bone Joint Surg. Am. 2014, 96, 135-142. [CrossRef] [PubMed]

163. Popelka, S.; Sosna, A.; Vavrik, P.; Jahoda, D.; Bartak, V.; Landor, I. [Eleven-Year Experience with Total Ankle Arthroplasty]. Acta Chir. Orthop. Traumatol. Cech. 2016, 83, 74-83. [PubMed]

164. Lamothe, J.; Deland, J.; Schon, L.; Saltzman, C.; Ellis, S. Total ankle replacement through a lateral approach. Tech. Foot Ankle Surg. 2015, 14, 69-78.

165. DeVries, J.G.; Derksen, T.A.; Scharer, B.M.; Limoni, R. Perioperative Complications and Initial Alignment of Lateral Approach Total Ankle Arthroplasty. J. Foot Ankle Surg. 2017, 56, 996-1000. [CrossRef] [PubMed]

166. Bianchi, A.; Martinelli, N.; Hosseinzadeh, M.; Flore, J.; Minoli, C.; Malerba, F.; Galbusera, F. Early clinical and radiological evaluation in patients with total ankle replacement performed by lateral approach and peroneal osteotomy. BMC Musculoskelet Disord. 2019, 20, 132. [CrossRef]

167. Usuelli, F.G.; Indino, C.; Maccario, C.; Manzi, L.; Salini, V. Total ankle replacement through a lateral approach: Surgical tips. SICOT J. 2016, 2, 38. [CrossRef]

168. Tan, E.W.; Maccario, C.; Talusan, P.G.; Schon, L.C. Early Complications and Secondary Procedures in Transfibular Total Ankle Replacement. Foot Ankle Int. 2016, 37, 835-841. [CrossRef]

169. Tiusanen, H.; Kormi, S.; Kohonen, I.; Saltychev, M. Results of Trabecular-Metal Total Ankle Arthroplasties With Transfibular Approach. Foot Ankle Int. 2020, 41, 411-418. [CrossRef]

170. Barg, A.; Bettin, C.C.; Burstein, A.H.; Saltzman, C.L.; Gililland, J. Early Clinical and Radiographic Outcomes of Trabecular Metal Total Ankle Replacement Using a Transfibular Approach. J. Bone Joint Surg. Am. 2018, 100, 505-515. [CrossRef]

171. Brigido, S.A.; DiDomenico, L.A. Primary Zimmer Trabecular Metal Total Ankle Replacement. In Primary and Revision Total Ankle Replacement; Roukis, T.S., Berlet, G.C., Bibbo, C., Hyer, C.F., Penner, M.J., Wünschel, M., Prissel, M.A., Eds.; Springer International Publishing: Cham, Switzerland, 2016; pp. 131-149.

172. Epperson, R.T.; Barg, A.; Williams, D.L.; Saltzman, C.L. Histological Analysis of a Retrieved Porous Tantalum Total Ankle Replacement: A Case Report. JBJS Case Connect. 2020, 10, e0379. [CrossRef]

173. Le Guehennec, L.; Soueidan, A.; Layrolle, P.; Amouriq, Y. Surface treatments of titanium dental implants for rapid osseointegration. Dent. Mater. 2007, 23, 844-854. [CrossRef] [PubMed]

174. Rupp, F.; Scheideler, L.; Olshanska, N.; de Wild, M.; Wieland, M.; Geis-Gerstorfer, J. Enhancing surface free energy and hydrophilicity through chemical modification of microstructured titanium implant surfaces. J. Biomed. Mater. Res. A 2006, 76, 323-334. [CrossRef] [PubMed]

175. Goldman, M.; Juodzbalys, G.; Vilkinis, V. Titanium surfaces with nanostructures influence on osteoblasts proliferation: A systematic review. J. Oral Maxillofac Res. 2014, 5. [CrossRef] 
176. De Arriba, C.C.; Alobera Gracia, M.A.; Coelho, P.G.; Neiva, R.; Tarnow, D.P.; Del Canto Pingarron, M.; Aguado-Henche, S. Osseoincorporation of Porous Tantalum Trabecular-Structured Metal: A Histologic and Histomorphometric Study in Humans. Int. J. Periodontics Restorative Dent. 2018, 38, 879-885. [CrossRef] [PubMed]

177. Lee, J.W.; Wen, H.B.; Gubbi, P.; Romanos, G.E. New bone formation and trabecular bone microarchitecture of highly porous tantalum compared to titanium implant threads: A pilot canine study. Clin. Oral Implants Res. 2018, 29, 164-174. [CrossRef] [PubMed]

178. El Chaar, E.; Castano, A. A Retrospective Survival Study of Trabecular Tantalum Implants Immediately Placed in Posterior Extraction Sockets Using a Flapless Technique. J. Oral Implantol. 2017, 43, 114-124. [CrossRef]

179. Bencharit, S.; Byrd, W.C.; Hosseini, B. Immediate placement of a porous-tantalum, trabecular metal-enhanced titanium dental implant with demineralized bone matrix into a socket with deficient buccal bone: A clinical report. J. Prosthet. Dent. 2015, 113, 262-269. [CrossRef]

180. Brauner, E.; Guarino, G.; Jamshir, S.; Papi, P.; Valentini, V.; Pompa, V.; Pompa, G. Evaluation of Highly Porous Dental Implants in Postablative Oral and Maxillofacial Cancer Patients: A Prospective Pilot Clinical Case Series Report. Implant. Dent. 2015, 24, 631-637. [CrossRef]

181. Papi, P.; Jamshir, S.; Brauner, E.; Di Carlo, S.; Ceci, A.; Piccoli, L.; Pompa, G. Clinical evaluation with 18 months follow-up of new PTTM enhanced dental implants in maxillo-facial post-oncological patients. Ann. Stomatol. 2014, 5, $136-141$.

182. Schlee, M.; Pradies, G.; Mehmke, W.U.; Beneytout, A.; Stamm, M.; Meda, R.G.; Kamm, T.; Poiroux, F.; Weinlich, F.; del Canto Pingarron, M.; et al. Prospective, Multicenter Evaluation of Trabecular Metal-Enhanced Titanium Dental Implants Placed in Routine Dental Practices: 1-Year Interim Report From the Development Period (2010 to 2011). Clin. Implant. Dent. Relat. Res. 2015, 17, 1141-1153. [CrossRef]

183. Dimaira, M. Immediate Placement of Trabecular Implants in Sites of Failed Implants. Int. J. Oral Maxillofac. Implants 2019, 34, 77-83. [CrossRef] [PubMed]

184. Schlee, M.; van der Schoor, W.P.; van der Schoor, A.R. Immediate loading of trabecular metal-enhanced titanium dental implants: Interim results from an international proof-of-principle study. Clin. Implant. Dent. Relat. Res. 2015, 17 (Suppl. 1), $308-320$. [CrossRef]

185. Edelmann, A.R.; Patel, D.; Allen, R.K.; Gibson, C.J.; Best, A.M.; Bencharit, S. Retrospective analysis of porous tantalum trabecular metal-enhanced titanium dental implants. J. Prosthet. Dent. 2019, 121, 404-410. [CrossRef] [PubMed]

186. Bencharit, S.; Byrd, W.C.; Altarawneh, S.; Hosseini, B.; Leong, A.; Reside, G.; Morelli, T.; Offenbacher, S. Development and applications of porous tantalum trabecular metal-enhanced titanium dental implants. Clin. Implant. Dent. Relat. Res. 2014, 16, 817-826. [CrossRef] [PubMed]

187. Bandyopadhyay, A.; Mitra, I.; Shivaram, A.; Dasgupta, N.; Bose, S. Direct comparison of additively manufactured porous titanium and tantalum implants towards in vivo osseointegration. Addit. Manuf. 2019, 28, 259-266. [CrossRef] [PubMed]

188. Wang, F.; Chen, H.; Yang, P.; Muheremu, A.; He, P.; Fan, H.; Yang, L. Three-dimensional printed porous tantalum prosthesis for treating inflammation after total knee arthroplasty in one-stage surgery—A case report. J. Int. Med. Res. 2020, 48, 300060519891280. [CrossRef] [PubMed]

189. Engesaeter, I.O.; Lie, S.A.; Lehmann, T.G.; Furnes, O.; Vollset, S.E.; Engesaeter, L.B. Neonatal hip instability and risk of total hip replacement in young adulthood: Follow-up of 2,218,596 newborns from the Medical Birth Registry of Norway in the Norwegian Arthroplasty Register. Acta Orthop. 2008, 79, 321-326. [CrossRef] [PubMed]

190. Cheng, L.; Zhao, D.; Yang, L.; Li, J.; Ma, Z.; Wang, Z.; Tian, F.; Tian, S. The application of 3D printed customized porous tantalum acetabular patch for adult DDH hip reconstruction. Chin. J. Orthop 2018, 38, 650-657.

191. Zhao, D.W.; Ma, Z.J.; Wang, T.N.; Liu, B.Y. Biocompatible Porous Tantalum Metal Plates in the Treatment of Tibial Fracture. Orthop. Surg. 2019, 11, 325-329. [CrossRef]

192. Zhou, R.; Ni, H.-J.; Peng, J.-H.; Liu, N.; Chen, S.; Shao, J.-H.; Fu, Q.-W.; Liu, J.-J.; Chen, F.; Qian, Q.-R. The mineralization, drug release and in vivo bone defect repair properties of calcium phosphates/PLA modified tantalum scaffolds. RSC Adv. 2020, 10, 7708-7717. [CrossRef]

193. Zhou, R.; Xu, W.; Chen, F.; Qi, C.; Lu, B.Q.; Zhang, H.; Wu, J.; Qian, Q.R.; Zhu, Y.J. Amorphous calcium phosphate nanospheres/polylactide composite coated tantalum scaffold: Facile preparation, fast biomineralization and subchondral bone defect repair application. Colloids Surf. B Biointerfaces 2014, 123, 236-245. [CrossRef] [PubMed]

194. Wang, Q.; Zhang, H.; Gan, H.; Wang, H.; Li, Q.; Wang, Z. Application of combined porous tantalum scaffolds loaded with bone morphogenetic protein 7 to repair of osteochondral defect in rabbits. Int. Orthop. 2018, 42, 1437-1448. [CrossRef] [PubMed]

195. Wang, N.; Li, H.; Wang, J.; Chen, S.; Ma, Y.; Zhang, Z. Study on the anticorrosion, biocompatibility, and osteoinductivity of tantalum decorated with tantalum oxide nanotube array films. ACS Appl. Mater. Interfaces 2012, 4, 4516-4523. [CrossRef]

196. Uslu, E.; Oztatli, H.; Garipcan, B.; Ercan, B. Fabrication and cellular interactions of nanoporous tantalum oxide. J. Biomed. Mater. Res. B Appl. Biomater. 2020, 108, 2743-2753. [CrossRef] [PubMed]

197. Gao, H.; Jie, Y.F.; Wang, Z.Q.; Wan, H.; Gong, L.; Lu, R.C.; Xue, Y.K.; Li, D.; Wang, H.Y.; Hao, L.N.; et al. Bioactive tantalum metal prepared by micro-arc oxidation and $\mathrm{NaOH}$ treatment. J. Mater. Chem. B 2014, 2, 1216-1224. [CrossRef]

198. Rodriguez-Contreras, A.; Guillem-Marti, J.; Lopez, O.; Manero, J.M.; Ruperez, E. Antimicrobial PHAs coatings for solid and porous tantalum implants. Colloids Surf. B Biointerfaces 2019, 182, 110317. [CrossRef] [PubMed] 
199. Liao, H.; Miao, X.; Ye, J.; Wu, T.; Deng, Z.; Li, C.; Jia, J.; Cheng, X.; Wang, X. Falling Leaves Inspired ZnO Nanorods-Nanoslices Hierarchical Structure for Implant Surface Modification with Two Stage Releasing Features. ACS Appl. Mater. Interfaces 2017, 9, 13009-13015. [CrossRef]

200. Garbuz, D.S.; Hu, Y.; Kim, W.Y.; Duan, K.; Masri, B.A.; Oxland, T.R.; Burt, H.; Wang, R.; Duncan, C.P. Enhanced gap filling and osteoconduction associated with alendronate-calcium phosphate-coated porous tantalum. J. Bone Joint Surg. Am. 2008, 90, 1090-1100. [CrossRef]

201. Tanzer, M.; Karabasz, D.; Krygier, J.J.; Cohen, R.; Bobyn, J.D. The Otto Aufranc Award: Bone augmentation around and within porous implants by local bisphosphonate elution. Clin. Orthop. Relat. Res. 2005, 441, 30-39. [CrossRef]

202. Wen, H.B.; Dalmeijer, R.A.J.; Cui, F.Z.; Van Blitterswijk, C.A.; De Groot, K. Preparation of calcium phosphate coating on porous tantalum. J. Mater. Sci. Lett. 1998, 17, 925-930.

203. Papanna, M.C.; Al-Hadithy, N.; Somanchi, B.V.; Sewell, M.D.; Robinson, P.M.; Khan, S.A.; Wilkes, R.A. The use of bone morphogenic protein-7 (OP-1) in the management of resistant non-unions in the upper and lower limb. Injury 2012, 43, 1135-1140. [CrossRef] [PubMed]

204. Dimitriou, R.; Dahabreh, Z.; Katsoulis, E.; Matthews, S.J.; Branfoot, T.; Giannoudis, P.V. Application of recombinant BMP-7 on persistent upper and lower limb non-unions. Injury 2005, 36 (Suppl. 4), S51-S59. [CrossRef] [PubMed]

205. Van Houwelingen, A.P.; McKee, M.D. Treatment of osteopenic humeral shaft nonunion with compression plating, humeral cortical allograft struts, and bone grafting. J. Orthop. Trauma 2005, 19, 36-42. [CrossRef]

206. Vinall, R.L.; Lo, S.H.; Reddi, A.H. Regulation of articular chondrocyte phenotype by bone morphogenetic protein 7, interleukin 1, and cellular context is dependent on the cytoskeleton. Exp. Cell Res. 2002, 272, 32-44. [CrossRef] [PubMed]

207. Zhao, Q.-M.; Li, G.-Z.; Yang, H.-L.; Gu, X.-F. Surface modification of biomedical tantalum by micro-arc oxidation. Mater. Technol. 2016, 32, 90-95. [CrossRef]

208. Bai, Y.; Park, I.S.; Lee, S.J.; Bae, T.S.; Duncan, W.; Swain, M.; Lee, M.H. One-step approach for hydroxyapatite-incorporated TiO2 coating on titanium via a combined technique of micro-arc oxidation and electrophoretic deposition. Appl. Surf. Sci. 2011, 257, 7010-7018. [CrossRef]

209. Hickok, N.J.; Shapiro, I.M.; Chen, A.F. The Impact of Incorporating Antimicrobials into Implant Surfaces. J. Dent. Res. 2018, 97, 14-22. [CrossRef]

210. Zeng, Q.; Zhu, Y.; Yu, B.; Sun, Y.; Ding, X.; Xu, C.; Wu, Y.W.; Tang, Z.; Xu, F.J. Antimicrobial and Antifouling Polymeric Agents for Surface Functionalization of Medical Implants. Biomacromolecules 2018, 19, 2805-2811. [CrossRef]

211. Raza, Z.A.; Abid, S.; Banat, I.M. Polyhydroxyalkanoates: Characteristics, production, recent developments and applications. Int. Biodeterior. Biodegrad. 2018, 126, 45-56. [CrossRef]

212. Rodríguez-Contreras, A.; García, Y.; Manero, J.M.; Rupérez, E. Antibacterial PHAs coating for titanium implants. Eur. Polym. J. 2017, 90, 66-78. [CrossRef] 